\title{
Immunotherapeutic Advances for NSCLC
}

\author{
Marco Massafra' ${ }^{1} *$ \\ Maria llenia Passalacqua $\mathbb{D}^{1}{ }^{1} *$ \\ Vittorio Gebbia ${ }^{2,3}$ \\ Paolo Macri ${ }^{4}$ \\ Chiara Lazzari $^{5}$ \\ Vanesa Gregorc ${ }^{5}$ \\ Carmelo Buda' \\ Giuseppe Altavilla' \\ Mariacarmela Santarpia (I) ${ }^{\prime}$
}

'Medical Oncology Unit, Department of Human Pathology "G. Barresi”,

University of Messina, Messina, Italy;

${ }^{2}$ Medical Oncology and Supportive Care

Unit, La Maddalena Cancer Center, Palermo, Italy; ${ }^{3}$ Department of Health Promotion, Mother and Child Care, Internal Medicine and Medical Specialties, University of Palermo, Palermo, Italy;

${ }^{4}$ Thoracic Surgery Unit, Humanitas Istituto Clinico Catanese, Catania, Italy; ${ }^{5}$ Department of Oncology, Università Vita-Salute, IRCCS-Ospedale San

Raffaele, Milano, Italy

*These authors contributed equally to this work
Correspondence: Mariacarmela Santarpia Medical Oncology Unit, Department of Human Pathology "G. Barresi”, University of Messina, via Consolare Valeria, I. Messina, 98125, Italy

Email mariacarmela.santarpia@unime.it

\begin{abstract}
Immunotherapy with antibodies against PD-1 or PD-L1, either alone or in combination with chemotherapy, has revolutionized treatment paradigms of non-small cell lung cancer (NSCLC) patients without oncogenic driver alterations. These agents, namely immune checkpoint inhibitors (ICIs), have also widely demonstrated a remarkable efficacy in locally advanced as well as in early-stage NSCLC. Assessment of tumor PD-L1 expression by immunohistochemistry has entered into routine clinical practice to select patients for immunotherapy, even though its predictive role has long been debated. Despite improved survival outcomes over standard chemotherapy, treatment with ICIs is associated with initial low response rate, with a significant proportion of patients not responding to these agents. Hence, novel appealing predictive biomarkers, such as those related to tumor cell signaling pathways, metabolism or the tumor microenvironment, have emerged as potentially useful to select those patients most likely to benefit from immunotherapy. Moreover, most patients ultimately develop acquired resistance to ICI treatment over time and novel therapeutic strategies are urgently needed to overcome or delay resistance. Herein, we provide an overview on recent advances in immunotherapy in NSCLC, focusing on updated results from studies on ICIs in different disease settings and at different lines of treatment. We further describe currently emerging predictive biomarkers, beyond PD-L1, to optimize patient selection and novel strategies to improve clinical outcomes.
\end{abstract}

Keywords: immunotherapy, anti-PD-1/PD-L1 antibodies, non-small cell lung cancer

\section{Introduction}

Lung cancer is the leading cause of cancer death worldwide, with an estimated 1.8 million deaths in 2020. ${ }^{1}$ Non-small cell lung cancer (NSCLC), which accounts for approximately $85 \%$ of all lung cancers, includes different histological types: squamous cell carcinoma, adenocarcinoma and large-cell carcinoma.

Molecularly targeted therapies have markedly improved the survival outcomes of patients with adenocarcinoma harboring specific oncogenic alterations, such as epidermal growth factor $(E G F R)$ mutations, anaplastic lymphoma kinase $(A L K)$ and ROS1 rearrangements. Other clinically actionable targets include $B R A F, M E T, R E T$ and $N T R K$, and the number of approved targeted agents is further expanding. Hence, molecular profiling of tumors represents a fundamental step in clinical practice to define the optimal treatment approach for each patient. ${ }^{2}$

In parallel to the discovery of novel potential druggable oncogenes, a deeper understanding of the mechanisms involved in anti-tumor immunity has led to the development of a number of immunotherapies, including the immune checkpoint inhibitors (ICIs). These agents activate the immune defense against tumors by overcoming the inhibitory effect of specific immunoregulatory molecules, the socalled checkpoints, including the programmed cell death-1 (PD-1)/programmed cell 
death ligand-1 (PD-L1) pathway and the cytotoxic T-lymphocyte antigen-4 (CTLA-4) pathway. ${ }^{3}$

Different monoclonal antibodies blocking the PD-1/ PD-L1 axis are currently approved, as monotherapy or in combination with chemotherapy, for use in clinical practice in different lines of treatment of advanced NSCLC. These include the anti-PD-1 nivolumab and pembrolizumab and the anti-PD-L1 atezolizumab and durvalumab. Tumor PD-L1 expression is currently tested in both squamous and non-squamous cell carcinoma as a predictive biomarker for these agents. The anti-PD-1 pembrolizumab is recommended as first-line treatment for NSCLC patients with high PD-L1 expression (tumor proportion score [TPS] $\geq 50 \%) .{ }^{4}$ For most patients with NSCLC and negative or low-positive PD-L1, the recommendation is the combination of pembrolizumab, carboplatin and pemetrexed or pembrolizumab, carboplatin and paclitaxel or nab-paclitaxel, depending on the histology. The activity of these agents in locally advanced tumors has also been well documented and data are emerging regarding their role as (neo)-adjuvant therapies.

Despite the overall superiority of ICIs compared to standard chemotherapy, responses are still not satisfactory, a proportion of patients experience early disease progression and most patients develop resistance during treatment. Therefore, key challenges remain, such as understanding the mechanisms of underlying primary and acquired resistance and how ICIs can be combined with other drugs in order to circumvent resistance and improve efficacy. There is a strong preclinical rationale demonstrating potential synergistic effects by combining different classes of ICIs, and this strategy has been confirmed in the clinical setting, leading to the approval of anti-CTLA-4 in combination with anti-PD-1 monoclonal antibodies as first-line treatment. Additional predictive biomarkers beyond PD-L1 expression, including tumor mutational burden (TMB), from tissue and/or liquid biopsy, are being investigated to identify the patients who are most likely to benefit from immunotherapy as well as those who are at higher risk of developing immune-related adverse events (irAEs). ${ }^{5}$

For this review, we identified references through a literature search of papers on "immunotherapy", "immune checkpoint inhibitors and NSCLC", "anti-PD-1/ PD-L1 antibodies and NSCLC" and "predictive biomarkers to immunotherapy", published up to June 2021, using PubMed, Scopus and Web of Science databases. We also searched for abstracts on the main international cancer congress (ASCO, ESMO, IASLC) websites. We collected and reviewed data for both completed and ongoing clinical trials.

\section{Immunotherapy in the Treatment of NSCLC}

The immune system plays a fundamental role in the recognition and elimination of pathogens and abnormal cells through the detection of non-self antigens, including cancer cells. ${ }^{6}$ It consists of "innate immunity", which is rapid and non-specific, and "adaptive immunity", with a delayed specific response, which mediates the immunological memory. Although many of the cellular components of both systems are capable of inducing the destruction of tumor cells, the mechanism used by immunological surveillance is mainly based on $\mathrm{T}$ lymphocytes, particularly cytotoxic, interferon- $\gamma$ (IFN- $\gamma)$-secreting $\mathrm{T}$ cells, which play a major role in killing malignant cells, thus hindering tumor progression. ${ }^{7}$

In the adaptive immune process, which leads $\mathrm{T}$ lymphocytes to the recognition of specific tumor antigens, a key role is played by dendritic cells, which act as antigen-presenting cells (APCs) and have the ability to bind these antigens to molecules of the major histocompatibility complex (MHC) and thus to present them to $\mathrm{CD}^{+}$ and $\mathrm{CD} 8^{+}$lymphocytes. Co-stimulatory molecules such as CD80 and CD86 on dendritic cells interact with the CD28 receptor on the membrane of $\mathrm{T}$ lymphocytes and contribute significantly to the activation of the T-mediated immune response. ${ }^{8}$

The immune response has specific mechanisms of regulation, the immune checkpoints, including molecules such as PD-1/PD-L1 and CTLA-4, which play a key role in the activation, proliferation and function of $\mathrm{T}$ lymphocytes. These checkpoints generally have the role of protecting healthy tissue from cytotoxic immune responses triggered by infections, but cancer cells can take advantage of these same checkpoints to avoid immunemediated destruction.

CTLA-4 is expressed on the surface of activated $\mathrm{T}$ lymphocytes and competes with the co-stimulatory receptor CD28 for binding to CD80 and CD86 ligands (also known as B7.1 and B7.2), expressed on APCs. Its greater affinity for these ligands generates an inhibitory signal that leads to the exhaustion of T-cells' anticancer functions and proliferative arrest, with the consequent survival of neoplastic clones. ${ }^{9}$ CTLA-4 can also cause depletion of CD80 and CD86 from the cell surface via "trans-endocytosis", to 
inhibit the transmission of CD28 stimulation signaling. This checkpoint suppresses anti-tumor immunity primarily in secondary lymphoid organs where early T-cell activation occurs, rather than within the tumor microenvironment.

PD-1 is an inhibitory, transmembrane receptor of the immunoglobulin superfamily B7, expressed by activated $\mathrm{T}$ lymphocytes upon antigen recognition by $\mathrm{T}$-cell receptors (TCRs), as well as by B lymphocytes and natural killer (NK) cells. The binding of PD-1 to one of its ligands, PD-L1 or PD-L2, enhances intracellular signals suppressing the activation of T cells and cytokine secretion, thereby inhibiting the anti-tumor response. ${ }^{10}$ Different studies have demonstrated that the induction of this pathway accelerates cancer progression and metastasis. ${ }^{11,12}$ PD-1 primarily inhibits T-cell activity in the effector phase within peripheral tissues, in which it has a physiological role in maintaining self-tolerance and restraining collateral tissue damage during infections, and in the tumor microenvironment. PD-L1 expression can be induced by inflammatory cytokines, mainly IFN- $\gamma$, produced by activated T cells and NK cells, on hematopoietic cells and other cell types, including epithelial and endothelial cells. Numerous tumor types, including NSCLC, express high PD-
L1 levels, suggesting a prominent role of this pathway as a mechanism to escape immune surveillance.

Furthermore, tumor cells can induce PD-L1 expression independently of inflammatory signals by a mechanism of innate immune resistance, which is identified in oncogenic signaling pathways such as PI3K/AKT, ALK/STAT3, MEK/ERK/STAT1 or EGFR. ${ }^{13-16}$

The expression of PD-L1 on solid tumors and the role of the PD-1 and CTLA-4 pathways in the escape from the immune response provided the rationale for evaluating them as potential targets for immunotherapy in cancer treatment (Figure 1). CTLA-4 inhibitors and PD-1/PD-L1 inhibitors can block those inhibitory signals by inducing the activation and proliferation of $\mathrm{T}$ cells to restore the function of killing tumor cells in patients with advanced cancer. ${ }^{17}$

Similarly to other tumors, lung cancer is able to escape immunosurveillance through various strategies, such as alteration of the antigen presentation mechanism, recruitment of regulatory $\mathrm{T}$ cells and activation of immune checkpoints. On the other hand, it is characterized by high rates of somatic mutations and this generates various tumor-specific antigens, increasing immunogenicity. ${ }^{18}$

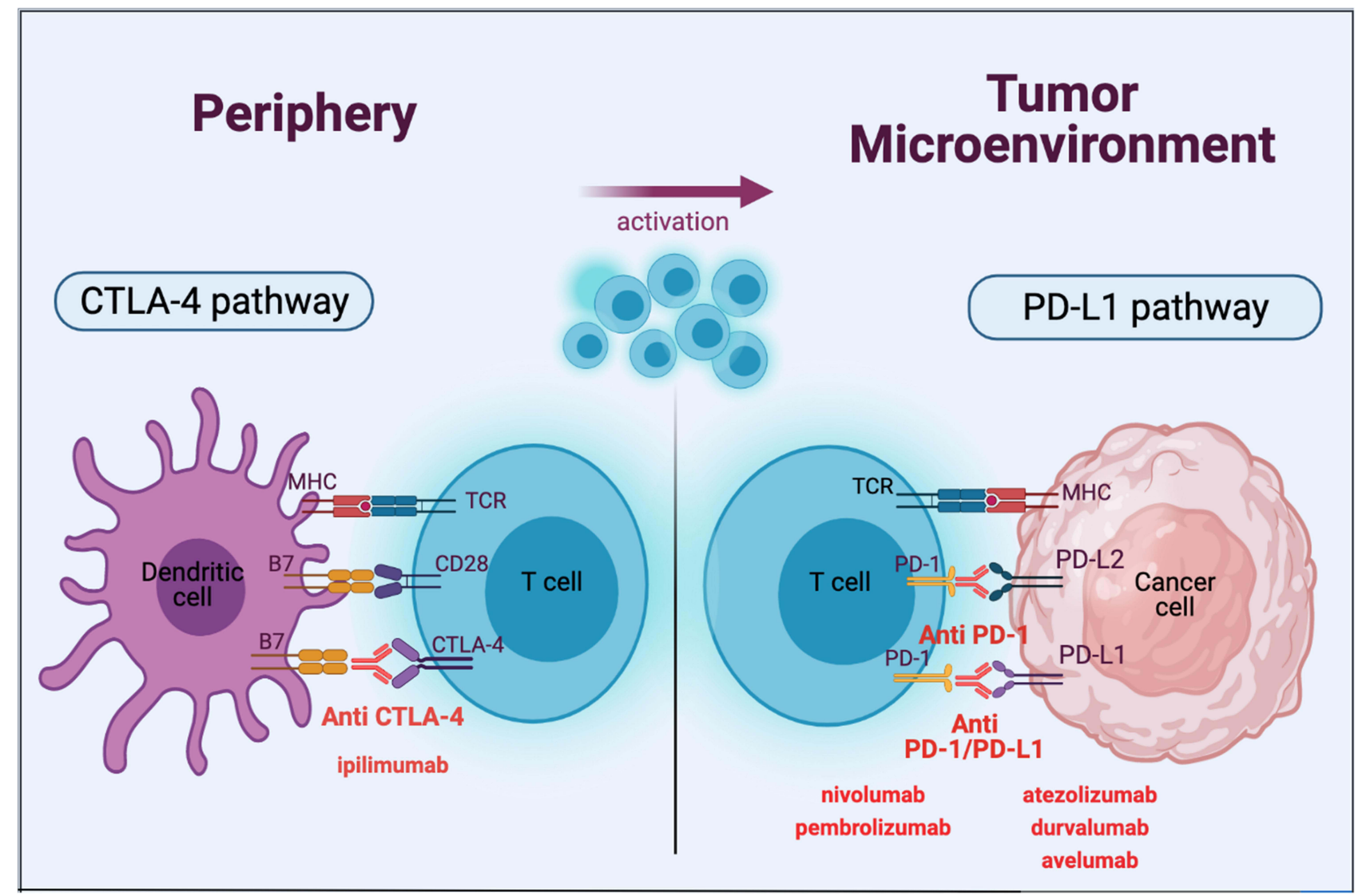

Figure I Immune checkpoint inhibitors. Created with BioRender.com. 
The activity of immune checkpoint inhibitors in the treatment of lung cancer was first demonstrated in 2012, in research exploring nivolumab responses and safety in metastatic NSCLC. ${ }^{19,20}$ Novel molecules have since been developed and clinically approved in different disease settings, thereby rapidly changing the scenario of treatment for NSCLC patients.

\section{Immune Checkpoint Inhibitors for Early-Stage NSCLC: Neoadjuvant/ Adjuvant Trials}

A small proportion of patients with newly diagnosed NSCLC are suitable for curative surgery. However, despite optimal surgical management, these patients have a high risk of recurrence (30-70\% of cases) owing to the presence of micrometastasis. ${ }^{21}$

Hence, perioperative strategies combined with surgery have been evaluated in order to reduce the risk of relapse, thereby improving survival. Cisplatin-based doublet chemotherapy is currently the standard of care for fit patients with radically resected stage II and III disease, based on positive results from large prospective, randomized trials of adjuvant chemotherapy and confirmed by metaanalyses. $^{22,23}$ Conversely, mediastinal post-operative radiotherapy (PORT) has not been demonstrated to improved disease-free survival (DFS) in patients with completely resected NSCLC with histologically/cytologically proven nodal involvement. Platinum-based chemotherapy can also be used in the neoadjuvant setting, with efficacy comparable to adjuvant chemotherapy. However, its use can have several advantages over adjuvant chemotherapy, including tumor downstaging, reducing R1-R2 resection rates and testing tumor susceptibility to specific drugs.

Other treatment strategies, including immunotherapy, have been tested to improve the clinical outcomes of earlystage NSCLC patients. Preclinical studies and early clinical trials support the use of a perioperative approach with ICIs (Table 1). CheckMate 159 was the first pilot study to explore the feasibility and safety of the PD-1 inhibitor nivolumab in untreated, surgically resectable early-stage (I-IIIA) NSCLC patients. Nivolumab (at a dose of $3 \mathrm{mg}$ per kilogram of body weight) was administered intravenously every 2 weeks, with surgery planned approximately 4 weeks after the first dose. Twenty-one patients were included (Table 1). The treatment had an acceptable sideeffect profile and was not associated with delays in surgery, but more than half of the video-assisted thoracoscopic surgery/robotic cases were converted to thoracotomy, often due to hilar inflammation and fibrosis. Two patients had a partial response (PR) and 18 stable disease (SD). All patients undergoing surgery were completely (R0) resected. A major pathological response (MPR), defined as $10 \%$ or less residual viable tumor cells in specimens after neoadjuvant chemotherapy, occurred in nine $(45 \%)$ of 20 resected tumors. PD-L1 expression was irrelevant with respect to the responses obtained. Instead, there was a correlation between PR and TMB. The recurrence rate within 18 months was $73 \%$ and the overall survival (OS) rate was $95 \%$. The 24 -month relapse-free survival (RFS) was $69 \%{ }^{24}$

In the phase IB ChiCTR-OIC-17013726 trial, 40 patients with resectable NSCLC (stage IA-IIIB) received two preoperative cycles of the PD-1 inhibitor sintilimab (200 mg, intravenously, day 1 out of 22) (Table 1). Thirty-seven patients underwent radical resection. Among these, 15 (40.5\%) achieved MPR, including six (16.2\%) with a pathological complete response (pCR) in the primary tumor. Squamous cell NSCLC showed a superior response to adenocarcinoma (MPR 48.4\% versus 0\%). Four patients experienced grade $\geq 3$ treatment-related adverse events (TRAEs). Of note, the decrease in tumor metabolism uptake as assessed by positron emission tomography (PET)/computed tomography (CT) scans after sintilimab correlated with the pathological response. Also, baseline PD-L1 expression on stromal cells instead of tumor cells was correlated with pathological regression, suggesting its role as a predictive biomarker to the anti-PD-1 inhibitor in this setting. ${ }^{25}$

The phase II randomized NEOSTAR trial assessed neoadjuvant nivolumab or nivolumab plus ipilimumab followed by surgery in 44 patients with operable NSCLC, with MPR as the primary endpoint. The nivolumab plus ipilimumab arm showed a $38 \%$ MPR rate, while a $22 \%$ MPR rate was observed with nivolumab (Table 1). The combination arm induced a higher $\mathrm{pCR}$ rate, fewer viable cells, and enhanced tumor immune infiltrates and immunological memory. ${ }^{26}$

The safety and efficacy of neoadjuvant atezolizumab have been evaluated in the phase II LCMC3 study, including patients with resectable, stage IB-IIIB NSCLC, who were given two cycles of atezolizumab $1200 \mathrm{mg}$ (days 1

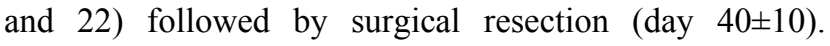
Patients with clinical benefit from neoadjuvant therapy could be treated with adjuvant atezolizumab for up to 12 months. Chemotherapy, with or without radiation, was 
Table I Clinical Trials of Neoadjuvant and Adjuvant Therapy with Immune Checkpoint Inhibitors for Early-Stage NSCLC

\begin{tabular}{|c|c|c|c|c|c|c|c|}
\hline Treatment & Phase & Stage & Trial Name & $\begin{array}{l}\text { No. of } \\
\text { Pts }\end{array}$ & PE & Results & $\begin{array}{l}\text { Status (NCT/ } \\
\text { Ref.) }\end{array}$ \\
\hline \multicolumn{8}{|l|}{ Neoadjuvant } \\
\hline Nivolumab & I & I-IIIA & $\begin{array}{l}\text { CheckMate } \\
159\end{array}$ & 21 & $\begin{array}{l}\text { Safety and } \\
\text { feasibility }\end{array}$ & MPR: 45\%; pCR $10 \%$ & Completed $^{24}$ \\
\hline Nivolumab + CT & ॥ & IIIA & NADIM & 46 & $\begin{array}{l}\text { PFS at } 24 \\
\text { months }\end{array}$ & $\begin{array}{c}\text { PFS: } 95.7 \% \text { at } 12 \text { months, } 87.0 \% \text { at } 18 \\
\text { months, } 77.1 \% \text { at } 24 \text { months }\end{array}$ & Completed $^{30}$ \\
\hline $\begin{array}{l}\text { Nivolumab vs } \\
\text { nivolumab + } \\
\text { ipilimumab }\end{array}$ & II & I-IIIA & NEOSTAR & 44 & $\begin{array}{l}\text { MPR; } \\
\text { ORR }\end{array}$ & $\begin{array}{c}\text { Nivo.: MPR: I7\%; Nivo. + Ipi.: MPR: } \\
38 \%\end{array}$ & Completed $^{26}$ \\
\hline $\begin{array}{l}\text { Nivolumab + CT vs } \\
C T\end{array}$ & II & IIIA/B & NADIM 2 & $90 *$ & $\mathrm{pCR}$ & - & $\begin{array}{c}\text { Ongoing } \\
\text { (NCT03838159) }\end{array}$ \\
\hline $\begin{array}{l}\text { Nivolumab + CT vs } \\
C T\end{array}$ & III & $\begin{array}{l}\text { IB- } \\
\text { IIIA }\end{array}$ & $\begin{array}{l}\text { CheckMate } \\
816\end{array}$ & $350 *$ & EFS; pCR & - & $\begin{array}{c}\text { Ongoing } \\
\text { (NCT02998528) }\end{array}$ \\
\hline Atezolizumab & ॥ & $\begin{array}{l}\text { IB- } \\
\text { IIIA }\end{array}$ & LCMC3 & $\begin{array}{l}101 / \\
180 *\end{array}$ & MPR & MPR: I8\%; pCR: 4.9\% & $\begin{array}{l}\text { Ongoing } \\
(\text { NCT0292730I })^{27}\end{array}$ \\
\hline Atezolizumab $+C T$ & II & $\begin{array}{l}\text { IB- } \\
\text { IIIA }\end{array}$ & $\begin{array}{l}\text { Columbia } \\
\text { University }\end{array}$ & 30 & MPR & MPR: $57 \% ;$ PCR: $33 \%$ & $\begin{array}{c}\text { Completed } \\
(\text { NCT027I6038) }\end{array}$ \\
\hline Atezolizumab & II & $\begin{array}{l}\text { IB- } \\
\text { IIIA }\end{array}$ & PRICNEPS & $60 *$ & Toxicity & - & $\begin{array}{c}\text { Ongoing } \\
\text { (NCT0299457) }\end{array}$ \\
\hline $\begin{array}{l}\text { Atezolizumab }+C T \\
\text { vs } C T\end{array}$ & III & II-IIIB & IMpower030 & $374 *$ & MPR; EFS & - & $\begin{array}{c}\text { Ongoing } \\
\text { (NCT03456063) }\end{array}$ \\
\hline Sintilimab & $\mathrm{lb}$ & $\begin{array}{l}\text { IA- } \\
\text { IIIB }\end{array}$ & $\begin{array}{l}\text { ChiCTR-OIC } \\
-17013726\end{array}$ & 40 & Safety & MPR: $40.5 \%$; pCR: $16.2 \%$ & Completed $^{25}$ \\
\hline Pembrolizumab & ॥ & $\begin{array}{l}\text { IB- } \\
\text { IIIA }\end{array}$ & TOP-I50I & $32 *$ & $\begin{array}{l}\text { Surgical } \\
\text { feasibility }\end{array}$ & - & $\begin{array}{c}\text { Ongoing } \\
\text { (NCT028I8920) }\end{array}$ \\
\hline $\begin{array}{l}\text { Pembrolizumab + CT } \\
\text { vs } C T\end{array}$ & III & II-IIIB & $\begin{array}{l}\text { KEYNOTE- } \\
671\end{array}$ & $786 *$ & EFS; OS & - & $\begin{array}{c}\text { Ongoing } \\
\text { (NCT03425643) }\end{array}$ \\
\hline $\begin{array}{l}\text { Durvalumab }+\mathrm{CT} \text { vs } \\
\mathrm{CT}\end{array}$ & III & $\begin{array}{l}\text { IIA- } \\
\text { IIIB }\end{array}$ & AEGEAN & $300 *$ & MPR & - & $\begin{array}{c}\text { Ongoing } \\
\text { (NCT03800134) }\end{array}$ \\
\hline \multicolumn{8}{|l|}{ Adjuvant } \\
\hline Nivolumab $\pm \mathrm{CT}$ & III & $\begin{array}{l}\text { IB- } \\
\text { IIIA }\end{array}$ & ANVIL & $903 *$ & OS; DFS & - & $\begin{array}{c}\text { Ongoing } \\
\text { (NCT02595944) }\end{array}$ \\
\hline Pembrolizumab $\pm \mathrm{CT}$ & III & $\begin{array}{l}\text { IB- } \\
\text { IIIA }\end{array}$ & $\begin{array}{l}\text { KEYNOTE- } \\
\text { 09I } \\
\text { (PEARLS) }\end{array}$ & $1380 *$ & DFS & - & $\begin{array}{c}\text { Ongoing } \\
\text { (NCT02504372) }\end{array}$ \\
\hline $\begin{array}{l}\text { Atezolizumab }+C T \\
\text { vs } C T\end{array}$ & III & $\begin{array}{l}\text { IB- } \\
\text { IIIA }\end{array}$ & IMpower0I0 & $1280 *$ & DFS & - & $\begin{array}{c}\text { Ongoing } \\
\text { (NCT024867/8) }\end{array}$ \\
\hline $\begin{array}{l}\text { Durvalumab vs } \\
\text { placebo } \pm C T\end{array}$ & III & $\begin{array}{l}\text { IB- } \\
\text { IIIB }\end{array}$ & BR3I & $1100 *$ & DFS & - & $\begin{array}{c}\text { Ongoing } \\
\text { (NCT02273375) }\end{array}$ \\
\hline
\end{tabular}

Note: *Number of patients estimated

Abbreviations: PE, primary endpoint; CT, chemotherapy; PFS, progression-free survival; MPR, major pathological response; ORR, overall response rate; PCR, pathological complete response; EFS, event-free survival; OS, overall survival; DFS, disease-free survival. 
allowed prior to adjuvant atezolizumab. Initial results on 101 patients showed an 18\% MPR rate in 82 evaluable patients with a pCR of $4.9 \%$. The therapy was well tolerated, with grade $\geq 3$ TRAEs in $6 \%$ of patients. In the primary analysis, the primary endpoint was met with an MPR rate of $21 \%$ and a pCR rate of $7 \%{ }^{27}$ At 1.5 years, the rates of DFS were $79 \%$ and $77 \%$ in the stage I/II and stage III groups, respectively, and the OS rates were $91 \%$ and $87 \%$ in patients with stage I/II and stage III disease, respectively. No new safety signals were observed. $^{28}$ The synergistic effect of combining chemotherapy and immunotherapy demonstrated in advanced NSCLC could also improve the efficacy of neoadjuvant approaches. Shu et al explored the activity of neoadjuvant atezolizumab in combination with carboplatin and nabpaclitaxel in resectable stage IB-IIIA NSCLC. Patients without disease progression after two cycles proceeded to receive two further cycles, followed by surgical resection. Thirty patients were enrolled in this study, the majority with disease stage IIIA. Twenty-nine (97\%) of 30 completed at least three cycles with all three drugs. A PR by RECIST criteria was observed in $63 \%$ of patients. Fiftyseven percent of patients had an MPR and 33\% had a pCR. Of note, $69 \%$ of patients with $\mathrm{N} 2$ disease at baseline had nodal downstaging. Pathological response was not associated with pretreatment PD-L1 expression, while an MPR was more frequently observed in patients with squamous cell carcinoma $(80 \%)$ than in those with adenocarcinoma (53\%) and was significantly associated with an objective response in a post-hoc analysis. Median DFS was 17.9 months and was longer in those patients with an MPR, although this was a post-hoc analysis including a small sample size. Among those patients who were tested for molecular predictive biomarkers, those with serine/threonine kinase 11 (STK11) mutations had no radiographic or pathological response. Treatment-related toxic effects did not compromise surgical resection and no surgical complications were attributable to neoadjuvant treatment. $^{29}$

The phase II NADIM was the first published trial reporting the anti-tumor activity and safety of nivolumab in combination with carboplatin and paclitaxel as neoadjuvant/adjuvant therapy in patients with resectable stage IIIA NSCLC. Patients received the neoadjuvant chemoimmunotherapy for three cycles before surgical resection, followed by adjuvant nivolumab monotherapy for 1 year. The primary endpoint was progression-free survival (PFS) at 24 months (Table 1). Among 46 patients enrolled, 41 patients underwent surgery with R0 resection and 37 received one or more cycles of adjuvant nivolumab, constituting the per-protocol population. At 24 months, PFS and OS were, respectively, $77.1 \%$ and $89.9 \%$ in the modified intention-to-treat (ITT) population and $87.9 \%$ and $97.3 \%$ in the per-protocol population. No patients had progressive disease during neoadjuvant therapy. Thirtyfour $(83 \%)$ of 41 patients who underwent surgery had an MPR, of whom 26 (63\%) had a pCR. Among these, $96.2 \%$ of patients were progression free at 18 and 24 months, which was significantly higher than for patients with incomplete or MPR. Of note, in this study 25 (54\%) of 46 patients had multiple level N2 disease, which commonly represents a challenge for surgery, therefore reinforcing the potential anti-tumor activity of this combination. PD-L1 expression and TMB were not associated with survival outcomes. Mutations of STK11, $K E A P 1, R B 1$ and EGFR were not associated with pathological response, but correlated with shorter PFS. The numbers of most immune populations analyzed were reduced in post-neoadjuvant samples, except for the numbers of memory and regulatory $\mathrm{T}$ cells, which seemed to have increased and were present in tumor areas that had a major or pCR compared with those that had an incomplete pathological response. TRAEs of grade 3 or worse were observed in $30 \%$ of patients during neoadjuvant treatment; none of the adverse events were associated with surgery delays or deaths. ${ }^{30}$

Phase III trials with immunochemotherapy are ongoing. KEYNOTE-671 is a randomized, double-blind, placebo-controlled trial exploring the combination of platinum doublet chemotherapy \pm pembrolizumab as neoadjuvant/adjuvant therapy for resectable stage IIB or IIIA NSCLC, with primary endpoints being event-free survival (EFS) and OS (NCT03425643). Other phase III trials that are measuring the potential clinical benefit of immunochemotherapy in the neoadjuvant setting are CheckMate 816 with nivolumab (NCT02998528), IMpower030 with atezolizumab (NCT03456063) and AEGEAN with durvalumab (NCT03800134) (Table 1).

Several phase III studies are currently being conducted to evaluate the role of ICIs after surgery as adjuvant therapy in early-stage NSCLC (Table 1). IMpower010 is a global phase III, randomized, open-label trial which evaluates atezolizumab versus best supportive care (BSC), following standard adjuvant cisplatin-based chemotherapy in patients with stage IB (tumors $\geq 4 \mathrm{~cm}$ ) to IIIA NSCLC (NCT02486718). At the planned interim analysis, IMpower010 met its primary endpoint, showing 
DFS benefit with adjuvant atezo versus BSC after adjuvant chemotherapy in patients with resected stage II-IIIA NSCLC, with pronounced benefit in the tumor PD-L1 $\geq 1 \%$ subgroup. OS data were still immature. The Adjuvant Nivolumab in Resected Lung Cancers (ANVIL) study compares nivolumab with observation after surgical resection and standard adjuvant chemotherapy and/or radiotherapy for stage IB-IIIA NSCLC (NCT02595944). KEYNOTE-091, also called PEARLS, is a phase III trial comparing pembrolizumab versus placebo, after adjuvant chemotherapy, in stage IB-IIIA NSCLC (NCT02504372).

The phase III BR31 (NCT02273375) is a double-blind, placebo-controlled randomized study of adjuvant durvalumab for 1 year in completely resected NSCLC (after receiving or not receiving standard adjuvant chemotherapy), which includes DFS in PD-L1-positive tumors as the primary endpoint.

\section{Immune Checkpoint Inhibitors in Locally Advanced NSCLC}

The PACIFIC trial led to a change in the treatment paradigm of patients with inoperable stage III NSCLC, for whom concurrent chemoradiotherapy (CRT) followed by observation has been the only available therapeutic approach until recently. In this randomized phase III trial, the anti-PD-L1 durvalumab $(10 \mathrm{mg} / \mathrm{kg}$, administered every 2 weeks) was compared with placebo as consolidation treatment for 1 year in patients with unresectable stage III NSCLC whose disease did not progress after concurrent CRT. The last radiation dose was administered 1-42 days before randomization and enrollment was not restricted to PD-L1 expression. Durvalumab met the coprimary endpoints for the study, and prolonged both PFS (16.8 versus 5.6 months; HR: $0.52, p<0.0001$ ) and OS (median not reached versus 28.7 months; HR: 0.68, $p=0.00251$ ). Moreover, durvalumab treatment was associated with a higher ORR and a longer time to distant metastasis. The drug exhibited a manageable safety profile and did not detrimentally impact patient-reported quality of life. ${ }^{31}$

Updated analyses at 4 years have been published and demonstrated durable PFS and sustained OS benefit with durvalumab. The median OS for durvalumab was 47.5 versus 29.1 months (HR: 0.71) for the placebo. Median PFS was 17.2 and 5.6 months (HR: 0.55) for durvalumab and placebo, respectively. Estimated 4-year OS rates were
$49.6 \%$ versus $36.3 \%$ for durvalumab versus placebo, and 4-year PFS rates were $35.3 \%$ versus $19.5 \%$, respectively. The OS benefit favored durvalumab across all PD-L1 subgroups except for patients with PD-L1 $<1 \%$. The time to first subsequent therapy or death and the time to second subsequent therapy or death were longer with durvalumab versus placebo. ${ }^{32}$

Starting durvalumab within 14 days from the end of CRT significantly improved PFS and OS. CRT can induce immunogenic cellular death, leading to the activation of cytotoxic $\mathrm{T}$ cells and subsequent expression of PD-L1 on the tumor cells, thereby improving sensitivity to the antiPD-L1 drug. ${ }^{33}$ Therefore, durvalumab has been approved by the EMA as maintenance therapy in non-progressing patients after concomitant CRT with platinum-based regimens only for PDL-1-positive disease.

Interesting results have been reported in the phase II KEYNOTE-799 trial, exploring pembrolizumab plus concomitant platinum chemotherapy and radiotherapy (cCRT) followed by consolidation pembrolizumab for unresectable, stage III NSCLC. The combination showed an ORR of approximately $70 \%$, with benefit observed regardless of PD-L1 TPS and tumor histology. The 12-month OS rates were $>80 \%$ in both cohorts (cohort A, including squamous and non-squamous NSCLC, receiving paclitaxel and carboplatin as the chemotherapy regimen; and cohort $\mathrm{B}$, including non-squamous NSCLC, receiving cisplatin and pemetrexed as the chemotherapy regimen) and the 12month PFS rates were approximately 70\%. The toxicity was manageable, with a grade $\geq 3$ pneumonitis incidence of $8 \%$ and $6.9 \%$ in the two different cohorts and an overall safety profile consistent with the toxicity profile of cCRT and of pembrolizumab in advanced disease. A phase III trial is ongoing to investigate pembrolizumab plus cCRT followed by pembrolizumab with or without olaparib in this setting (KEYLYNK-12 study; NCT04380636).

\section{Immune Checkpoint Inhibitors in First-Line Treatment of Metastatic NSCLC}

In patients with metastatic squamous and non-squamous NSCLC who do not harbor a targetable genetic alteration, the use of ICIs, with or without chemotherapy, has, over the last few years, become the standard of care. Pembrolizumab represents the first-in-class drug to receive FDA approval for treatment-naïve, metastatic NSCLC patients, in accordance with PD-L1 expression (TPS) 
$\geq 50 \%$ and without driver mutations, following the favorable results of the KEYNOTE-024 trial (Table 2). In this study, pembrolizumab showed superior efficacy to platinum-based chemotherapy in terms of median PFS (10.3 versus 6 months; HR: $0.50, p<0.001)$, OS (6-month OS rate of $80.2 \%$ versus $72.4 \%$; HR: $0.60, p=0.005$ ), RR (44.8\% versus $27.8 \%$ ) and duration of response (DOR). ${ }^{34}$ Pembrolizumab was also associated with fewer adverse events than was platinum-based chemotherapy. In the 5-year follow-up analysis, median OS was 26.3 months

Table 2 Randomized Trials with Immune Checkpoint Inhibitors in First-Line Treatment in Advanced NSCLC

\begin{tabular}{|c|c|c|c|c|c|c|}
\hline Treatment & Trial Name & $\begin{array}{c}\text { No. of } \\
\text { Patients }\end{array}$ & $\begin{array}{c}\text { Characteristics } \\
\text { of Patients }\end{array}$ & $\begin{array}{c}\text { Survival } \\
\text { EP }\end{array}$ & Results & Ref. \\
\hline \multicolumn{7}{|l|}{ ICI monotherapy } \\
\hline \multirow[t]{2}{*}{ Nivolumab vs CT alone } & \multirow{2}{*}{$\begin{array}{l}\text { CheckMate } \\
026\end{array}$} & \multirow{2}{*}{$\begin{array}{c}423 \\
(21 I \text { vs } 212)\end{array}$} & \multirow[t]{2}{*}{ PD-LI $\geq 5 \%$} & PFS & 4.2 vs 5.9 months (HR: 1.05$)$ & \multirow[t]{2}{*}{ [36] } \\
\hline & & & & OS & I 4.4 vs I3.2 months (HR: I.02) & \\
\hline \multirow[t]{2}{*}{ Pembrolizumab vs $\mathrm{CT}$ alone } & \multirow{2}{*}{$\begin{array}{l}\text { KEYNOTE } \\
024\end{array}$} & \multirow{2}{*}{$\begin{array}{c}305 \\
\text { (I54 vs I5I) }\end{array}$} & \multirow[t]{2}{*}{ PD-LI $\geq 50 \%$} & PFS & I0.3 vs 6.0 months (HR: 0.50$)$ & \multirow[t]{2}{*}{ [34] } \\
\hline & & & & OS & 26.3 vs 13.4 months (HR: 0.62$)$ & \\
\hline \multirow[t]{2}{*}{ Pembrolizumab vs $\mathrm{CT}$ alone } & \multirow{2}{*}{$\begin{array}{l}\text { KEYNOTE } \\
042\end{array}$} & \multirow{2}{*}{$\begin{array}{c}1275 \\
(638 \text { vs } 637)\end{array}$} & \multirow[t]{2}{*}{ PD-LI $\geq 1 \%$} & PFS & 5.4 vs 6.5 months (HR: I.07) & \multirow[t]{2}{*}{ [101] } \\
\hline & & & & OS & I6.7 vs 12.1 months (HR: $0.8 I)$ & \\
\hline Atezolizumab vs $\mathrm{CT}$ alone & IMpowerIIO & $\begin{array}{c}205 \\
(107 \text { vs } 98)\end{array}$ & PD-LI $\geq 50 \%$ & OS & 20.2 vs 13.1 months (HR: 0.59$)$ & [37] \\
\hline \multicolumn{7}{|l|}{$\mathrm{ICl}$ combination } \\
\hline \multirow[t]{2}{*}{$\begin{array}{l}\text { Nivolumab }+ \text { ipilimumab vs } \\
\text { nivolumab vs CT alone }\end{array}$} & \multirow[t]{2}{*}{$\begin{array}{l}\text { CheckMate } \\
227\end{array}$} & \multirow{2}{*}{$\begin{array}{c}1189 \\
(396 \text { vs } 396 \\
\text { vs } 397)\end{array}$} & \multirow[t]{2}{*}{ PD-LI $\geq 1$} & PFS & $\begin{array}{c}\text { Nivo. + Ipi. vs CT: } 7.2 \text { vs } 5.5 \text { months } \\
\text { (HR: } 0.58)\end{array}$ & \multirow[t]{2}{*}{ [4I] } \\
\hline & & & & OS & $\begin{array}{c}\text { Nivo. + Ipi. vs CT: } 17.1 \text { vs } 14.9 \text { months } \\
\text { (HR: } 0.79 \text { ) }\end{array}$ & \\
\hline \multirow[t]{2}{*}{$\begin{array}{l}\text { Durvalumab } \pm \\
\text { tremelimumab vs CT alone }\end{array}$} & \multirow[t]{2}{*}{ MYSTIC } & \multirow[t]{2}{*}{1118} & PD-LI $\geq 25 \%$ & OS & $\begin{array}{c}\text { Durvalumab vs CT: } 16.3 \text { vs } 12.9 \text { months } \\
\text { (HR: } 0.76)\end{array}$ & \multirow[t]{2}{*}{ [42] } \\
\hline & & & $\begin{array}{c}\text { TMB } \geq 20 \text { mut } / \\
\text { megabase }\end{array}$ & OS & $\begin{array}{c}\text { Durv. + Trem. vs CT: } 21.9 \text { vs } 10.0 \\
\text { months (HR: } 0.49)\end{array}$ & \\
\hline \multicolumn{7}{|l|}{$\mathrm{ICI}+\mathrm{CT}$ combination } \\
\hline \multirow{3}{*}{$\begin{array}{l}\text { Pembrolizumab + CT vs CT } \\
\text { alone }\end{array}$} & \multirow{3}{*}{$\begin{array}{l}\text { KEYNOTE } \\
189\end{array}$} & \multirow{3}{*}{$\begin{array}{c}616 \\
(410 \text { vs 206) }\end{array}$} & \multirow{3}{*}{$\begin{array}{l}\text { Non-squamous } \\
\text { tumors }\end{array}$} & PFS & 9.0 vs 4.9 months (HR 0.48 ) & \multirow[t]{3}{*}{ [44] } \\
\hline & & & & OS & 22.0 vs 10.07 months (HR: 0.56$)$ & \\
\hline & & & & PFS-2 & 17.0 vs 9.0 months (HR: 0.49$)$ & \\
\hline \multirow{2}{*}{$\begin{array}{l}\text { Pembrolizumab + CT vs CT } \\
\text { alone }\end{array}$} & \multirow{2}{*}{$\begin{array}{l}\text { KEYNOTE } \\
407\end{array}$} & 559 & Squamous tumors & PFS & 6.4 vs 4.8 months (HR: 0.56 ) & [45] \\
\hline & & & & OS & I5.9 vs II. 3 months (HR: 0.64$)$ & \\
\hline$A C P$ vs $A B C P$ vs $B C P$ & IMpower 150 & $\begin{array}{c}1202 \\
(402 \text { vs } 400\end{array}$ & $\begin{array}{l}\text { Non-squamous } \\
\text { tumors }\end{array}$ & PFS & $\begin{array}{c}A B C P \text { vs } B C P: 8.3 \text { vs } 6.8 \text { months (HR: } \\
0.62)\end{array}$ & [47] \\
\hline & & vs 400 ) & & OS & $\begin{array}{c}A B C P \text { vs } B C P: \mid 9.2 \text { vs } \mid 4.7 \text { months (HR: } \\
0.78)\end{array}$ & \\
\hline $\begin{array}{l}\text { Nivolumab }+ \text { ipilimumab }+ \\
2 \text { cycles of } C T \text { vs CT alone }\end{array}$ & $\begin{array}{l}\text { CheckMate } \\
\text { 9LA }\end{array}$ & $\begin{array}{c}719 \\
(361 \text { vs } 358)\end{array}$ & $\begin{array}{l}\text { Squamous and } \\
\text { non-squamous } \\
\text { tumors }\end{array}$ & OS & I5.6 vs 10.9 months (HR: 0.66$)$ & [48] \\
\hline
\end{tabular}

Abbreviations: EP, endpoint; ICI, immune checkpoint inhibitor; CT, chemotherapy; PD-LI, programmed cell death ligand-I; TMB, tumor mutational burden; PFS, progression-free survival; OS, overall survival; PFS-2, time from randomization to progression on next-line therapy; HR, hazard ratio; ACP, atezolizumab + carboplatin + paclitaxel; ABCP, atezolizumab + bevacizumab + carboplatin + paclitaxel; BCP, bevacizumab + carboplatin + paclitaxel. 
for pembrolizumab and 13.4 months for chemotherapy (HR: 0.62). Among those patients who received 35 cycles of pembrolizumab, the majority $(82.1 \%)$ were still alive at approximately 5 years. Of note, toxicity did not increase with a longer treatment exposure. ${ }^{35}$ In the phase III CheckMate 026 study, nivolumab as a single agent was not associated with longer PFS and OS than chemotherapy in stage IV NSCLC patients with PD-L1 of $\geq 5 \% .{ }^{36}$ Atezolizumab as monotherapy (IMpower110 trial) significantly improved OS compared to chemotherapy alone (cisplatin or carboplatin and pemetrexed or gemcitabine), in patients with metastatic NSCLC with PD-L1 expression of $\geq 50 \%$ (median OS: 20.2 versus 13.1 months; HR: $0.595, p=0.01$ ), and was associated with fewer grade 3-4 $\mathrm{AEs}^{37}$ (Table 2). In a phase IB study (JAVELIN Solid Tumor trial; NCT01772004), the anti-PD-L1 avelumab also showed anticancer activity with a tolerable safety profile as a first-line treatment in patients with metastatic or recurrent NSCLC. Objective responses were observed in $19.9 \%$ of patients and were durable (mDOR of 12.0 months). Median PFS and OS were 4 and 14.1 months, respectively. These data support further investigation of avelumab in the phase III JAVELIN Lung 100 study. ${ }^{38}$ Combinatorial therapeutic strategies, including combinations of different classes of ICIs or ICIs with chemotherapy, have been developed to improve the efficacy of single agents. Indeed, cytotoxic chemotherapy could have potential immunogenic effects, such as by inducing tumor cell destruction and antigen presentation by dendritic cells, thereby acting synergistically with immunotherapy, particularly in those tumors that are less responsive to ICI alone. The combination of anti-PD-1 and anti-CTLA-4 in first-line treatment was tested in an openlabel, phase I, multicohort study, CheckMate 012, including stage IIIB or stage IV, treatment-naïve NSCLC patients. The association of nivolumab $3 \mathrm{mg} / \mathrm{kg}$ every 2 weeks with ipilimumab $1 \mathrm{mg} / \mathrm{kg}$ every 6 or 12 weeks had an acceptable safety profile and demonstrated promising clinical activity, as shown by high RR (ranging from 38\% to $47 \%$ ) and durable responses. Confirmed responses were higher in patients with PD-L1 on tumor cells $\geq 1 \%{ }^{39}$ Nivolumab plus low-dose ipilimumab was demonstrated to be tolerable and effective in the first-line setting in the phase II CheckMate 568 study. Of note, in this study ORR and PFS were significantly improved with the ICI doublet in patients with high TMB $(\geq 10$ mutations per megabase; mut/Mb), regardless of PD-L1 expression. ${ }^{40}$ The predictive value of TMB was further demonstrated by two phase
III studies with ICI combinations. In CheckMate 227, PFS was significantly longer in the nivolumab plus ipilimumab arm compared with chemotherapy ( 7.2 versus 5.5 months; HR: $0.58, p<0.001)$, in the first-line setting in patients with high TMB $(\geq 10 \mathrm{mut} / \mathrm{Mb})$, regardless of PD-L1 expression. ${ }^{41}$ Likewise, in the MYSTIC study, which did not meet the primary endpoints of improved OS with durvalumab or durvalumab plus tremelimumab versus chemotherapy in patients with PD-L1 $\geq 25 \%$, exploratory analysis showed an improved survival benefit with durvalumab and tremelimumab versus chemotherapy in those patients with blood TMB of $\geq 20$ mut/Mb. ${ }^{42}$ The KEYNOTE-189 trial compared a combination of pemetrexed-platinum with either pembrolizumab or placebo in advanced non-squamous NSCLC with any level of PD-L1 expression and without any oncogenic drivers. In this trial, pembrolizumab demonstrated substantially improved OS and PFS. The survival benefit with pembrolizumab was observed in all subgroups of PD-L1 TPS, including patients with a score of less than $1 \%$ with a manageable safety profile. ${ }^{43}$ From the latest update, with a median follow-up of 23.1 months, treatment with pembrolizumab and chemotherapy continued to improve OS and PFS over the placebo group. Median OS was 22.0 months in the pembrolizumab-combination group versus 10.7 months in the placebo-combination group (HR: 0.56 ; 95\% CI, 0.45 to 0.70). Median PFS was 9.0 and 4.9 months, respectively (HR: 0.48 ; 95\% CI, 0.40 to 0.58 ). Median PFS-2, defined as the time from randomization to progression on next-line therapy or death, was 17 versus 9 months. Benefits in terms of OS and PFS were observed regardless of PD-L1 expression or the presence of liver or brain metastases. ${ }^{44}$ Pembrolizumab-based immunochemotherapy combination has also shown clinical benefit in squamous tumors. In the KEYNOTE-407 trial, 559 patients with untreated metastatic squamous NSCLC received pembrolizumab or placebo for up to 35 cycles with carboplatin and either paclitaxel or nab-paclitaxel for the first four cycles. First published results showed that pembrolizumab plus chemotherapy was associated with clinically meaningful improvement over placebo plus chemotherapy in median OS (15.9 versus 11.3 months; HR: $0.64, p<0.001)$, PFS (6.4 versus 4.8 months; HR: $0.56, p<0.001$ ) and objective responses (Table 2). Survival benefit was observed regardless of tumor PD-L1 expression. Immune-mediated adverse events were more frequently observed in the pembrolizumab-combination group. ${ }^{45}$ Updated efficacy outcomes confirmed that pembrolizumab plus chemotherapy 
continued to exhibit improved OS and PFS in patients with metastatic squamous NSCLC, with a longer PFS-2 compared to placebo. These results further support the use of upfront immunochemotherapy association in squamous NSCLC. ${ }^{46}$ The phase III trial IMpower150 evaluated the efficacy and safety of atezolizumab in combination with bevacizumab and chemotherapy in metastatic nonsquamous NSCLC with any level of PD-L1 expression. ${ }^{47}$ Co-primary endpoints were PFS and OS in the wild-type population (WT), without $E G F R$ or $A L K$ genomic alterations, and PFS among WT patients with high expression of the effector T-cell gene signature, established as a sensitive predictive biomarker in the previous phase III OAK trial. Atezolizumab with bevacizumab plus carboplatin and paclitaxel (ABCP) demonstrated longer PFS compared to bevacizumab and chemotherapy (BCP) in the WT population (8.3 versus 6.8 months; HR: $0.62, p<0.001)$ and in the Teff-high population (11.3 versus 6.8 months; HR: 0.51 , $p<0.001$ ) (Table 2). ABCP also improved PFS in the entire ITT population, including patients with EGFR mutations or $A L K$ rearrangements (who had progressed on or were intolerant to tyrosine kinase inhibitors [TKIs]), and among those with low or negative PD-L1 expression and those with liver metastases. Median OS was also longer in the ABCP group than in the BCP group (19.2 versus 14.7 months; HR: $0.78, p=0.02)$. The safety profile was consistent with the toxicity of the individual drugs. Grade 3-4 TRAEs and serious adverse events (SAEs) were observed in $55.7 \%$ and $47.7 \%$ and in $25.4 \%$ and $19.3 \%$ of patients in the ABCP and BCP groups, respectively. The majority of immune-related AEs were of grades 1 and 2. ${ }^{47}$ Despite the absence of significant differences in OS between the combination of durvalumab with tremelimumab and durvalumab and tremelimumab plus chemotherapy in the CCTG BR.34 trial, the planned exploratory analyses demonstrated an improved OS with durvalumab, tremelimumab and chemotherapy for the subgroup of patients with PD-L1 TPS $\geq 50 \%$, and, in both treatment groups, patients with blood TMB $<20$ mutations per megabase had poor survival. In this study, toxicity was greater in the durvalumab, tremelimumab and chemotherapy arm. The use of a combined immunotherapeutic approach could limit the use of cytotoxic chemotherapy in the firstline setting, thereby potentially limiting chemotherapyrelated toxicities. The association of different checkpoint inhibitors in association with a short course of chemotherapy has also emerged as an effective therapeutic strategy. In the CheckMate 9LA trial, nivolumab plus ipilimumab with two cycles of platinum-based chemotherapy (histology-based) provided a significant improvement in OS compared to chemotherapy alone (median OS: 15.6 versus 10.9 months; HR: 0.66) in metastatic NSCLC patients. Improved $\mathrm{OS}$ in the experimental group versus the control group was observed across all PD-L1 expression levels and regardless of histology. Of note, patients with stable CNS metastases, although representing a small subgroup, derived benefit from this approach. Response rates and PFS were also improved in the experimental group compared with the control group, regardless of PD-L1 expression level or tumor histology. Grade 3-4 TRAEs occurred in $47 \%$ versus $38 \%$ of patients, leading to treatment discontinuation in $16 \%$ and $5 \%$ of patients in the experimental group and control group, respectively. Treatmentrelated SAEs of grade 3-4 were reported in $25 \%$ and $15 \%$ of patients in the two groups. ${ }^{48}$

Additional immunotherapeutic agents have been tested in metastatic NSCLC patients. In January 2021, the FDA granted Breakthrough Therapy Designation (BTD) to tiragolumab in combination with atezolizumab for the first-line treatment of NSCLC patients with high PD-L1 expression and no EGFR or ALK genomic tumor aberrations. Tiragolumab is a monoclonal antibody designed to bind with TIGIT, an inhibitory receptor expressed on multiple immune cells, including T cells and NK cells. TIGIT binds to a poliovirus receptor (PVR, or CD155) on tumor cells and APCs. By binding to TIGIT, tiragolumab blocks its interaction with the PVR, and can restore the anti-tumor activity of T cells and NK cells. This drug acts synergistically with antiPD-1/PD-L1 agents, as demonstrated in preclinical models. ${ }^{49}$ The randomized, placebo-controlled, phase II CITYSCAPE trial assessed the efficacy and safety of a combination of tiragolumab with atezolizumab compared to placebo with atezolizumab in locally advanced or metastatic, PD-L1positive (TPS $\geq 1 \%$ ) NSCLC patients. At a median followup of 10.9 months, the combination of tiragolumab and atezolizumab showed clinically meaningful improvement in ORR compared to placebo and atezolizumab (37\% versus $21 \%$, respectively) and a $42 \%$ reduction in the risk of progression or death compared with atezolizumab alone. The subgroup with high levels of PD-L1 (TPS $\geq 50 \%$ ) had markedly improved ORR (66\% versus $24 \%$ ) and median PFS (NR versus 4.11 months) in the tiragolumab with atezolizumab arm compared with the placebo arm. ${ }^{50}$ Tiragolumab plus atezolizumab was well tolerated and the safety profile was similar to placebo and atezolizumab. Immune-mediated AEs were more frequent with tiragolumab, but were mainly of 
grades 1 and 2 and manageable. The phase III study SKYSCRAPER-01, on tiragolumab and atezolizumab in first-line PD-L1 $\geq 50 \%$ NSCLC, is ongoing (NCT04294810).

\section{Immune Checkpoint Inhibitors in Pretreated NSCLC}

The first approval for ICIs in advanced NSCLC was granted for pretreated patients, based on demonstration of a significant benefit of anti-PD-1 and anti-PD-L1 over second-line chemotherapy in terms of OS as well as tolerability in randomized phase III studies.

Two large, randomized trials, CheckMate 017 and CheckMate 057, established nivolumab as a standard of care for the second-line treatment of advanced NSCLC (Table 3).
CheckMate 017 evaluated the efficacy of nivolumab versus docetaxel in patients with advanced squamous cell carcinoma, who had previously undergone platinum-based doublets. Median OS was 9.2 months in the nivolumab arm and 6 months in the docetaxel arm (HR: $0.59, p<0.001$ ). The 1-year survival rate was $42 \%$ with nivolumab versus $24 \%$ with docetaxel. The anti-PD-1 drug demonstrated a consistent, statistically and clinically significant improvement in all secondary endpoints (ORR, PFS and quality of life), and benefit was seen regardless of PD-L1 level. ${ }^{51}$

CheckMate 057 randomized patients with advanced non-squamous carcinoma and, as in CheckMate 017, all patients had progressed on first-line platinum doublet chemotherapy. Patients with EGFR- and $A L K$-mutated NSCLC had to have progressed on appropriate TKI therapy. Median OS was higher for nivolumab than for

Table 3 Randomized Phase III Clinical Trials with Immune Checkpoint Inhibitors in Pretreated mNSCLC

\begin{tabular}{|c|c|c|c|c|c|c|c|c|c|c|c|}
\hline \multirow{3}{*}{$\begin{array}{l}\text { Trial } \\
\text { Name } \\
\text { CheckMate } \\
017\end{array}$} & \multirow{3}{*}{$\begin{array}{c}\text { Histology, } \\
\text { PD-LI }\end{array}$} & \multirow{2}{*}{$\begin{array}{c}\text { Treatment Arms } \\
\begin{array}{c}\text { Nivolumab } 3 \mathrm{mg} / \mathrm{kg} \text { every } 2 \\
\text { weeks }\end{array}\end{array}$} & \multirow{2}{*}{$\begin{array}{c}\begin{array}{c}\text { No. of } \\
\text { Patients }\end{array} \\
135\end{array}$} & \multicolumn{2}{|c|}{$\begin{array}{c}\text { mPFS } \\
\text { (Months) }\end{array}$} & \multicolumn{2}{|c|}{$\begin{array}{c}\text { mOS } \\
\text { (Months) }\end{array}$} & \multirow{2}{*}{$\begin{array}{c}\text { I-year } \\
\text { OS }\end{array}$} & \multirow{2}{*}{$\begin{array}{l}\text { ORR } \\
20 \%\end{array}$} & \multirow{2}{*}{$\begin{array}{c}\begin{array}{c}\text { Grade } \geq 3 \\
\text { TRAE }\end{array} \\
7 \%\end{array}$} & \multirow{2}{*}{$\begin{array}{l}\text { Ref. } \\
{[51]}\end{array}$} \\
\hline & & & & 3.5 & $\begin{array}{l}\text { HR: } \\
0.62\end{array}$ & 9.2 & $\begin{array}{l}\text { HR: } \\
0.59\end{array}$ & & & & \\
\hline & & $\begin{array}{c}\text { Docetaxel } 75 \mathrm{mg} / \mathrm{m}^{2} \text { every } 3 \\
\text { weeks }\end{array}$ & 137 & 2.8 & & 6.0 & & $24 \%$ & $9 \%$ & $55 \%$ & \\
\hline \multirow[t]{2}{*}{$\begin{array}{l}\text { CheckMate } \\
057\end{array}$} & \multirow[t]{2}{*}{$\begin{array}{l}\text { Non- } \\
\text { squamous }\end{array}$} & $\begin{array}{c}\text { Nivolumab } 3 \mathrm{mg} / \mathrm{kg} \text { every } 2 \\
\text { weeks }\end{array}$ & 292 & 2.3 & \multirow[t]{2}{*}{$\begin{array}{l}\text { HR: } \\
0.92^{*}\end{array}$} & 12.2 & \multirow[t]{2}{*}{$\begin{array}{l}\text { HR: } \\
0.73\end{array}$} & $51 \%$ & $19 \%$ & $10 \%$ & \multirow[t]{2}{*}{ [52] } \\
\hline & & $\begin{array}{c}\text { Docetaxel } 75 \mathrm{mg} / \mathrm{m}^{2} \text { every } 3 \\
\text { weeks }\end{array}$ & 290 & 4.2 & & 9.4 & & $39 \%$ & $12 \%$ & $54 \%$ & \\
\hline \multirow[t]{3}{*}{$\begin{array}{l}\text { KEYNOTE } \\
010\end{array}$} & \multirow[t]{3}{*}{$\begin{array}{l}\text { Both with } \\
\text { PD-LI } \geq \text { I }\end{array}$} & $\begin{array}{c}\text { Pembrolizumab } 2 \mathrm{mg} / \mathrm{kg} \text { every } \\
3 \text { weeks }\end{array}$ & 345 & 3.9 & & 10.4 & & & $18 \%$ & $13 \%$ & \multirow[t]{3}{*}{ [54] } \\
\hline & & $\begin{array}{c}\text { Pembrolizumab } 10 \mathrm{mg} / \mathrm{kg} \\
\text { every } 3 \text { weeks }\end{array}$ & 346 & 4.0 & \multirow[t]{2}{*}{$\begin{array}{l}\text { HR: } \\
0.79\end{array}$} & 12.7 & \multirow[t]{2}{*}{$\begin{array}{l}\text { HR: } \\
0.6 \mathrm{I}\end{array}$} & & $18 \%$ & $16 \%$ & \\
\hline & & $\begin{array}{c}\text { Docetaxel } 75 \mathrm{mg} / \mathrm{m}^{2} \text { every } 3 \\
\text { weeks }\end{array}$ & 343 & 4.0 & & 8.5 & & & $9 \%$ & $35 \%$ & \\
\hline \multirow[t]{2}{*}{ OAK } & \multirow[t]{2}{*}{ Both } & $\begin{array}{c}\text { Atezolizumab } 1200 \mathrm{mg} \text { fixed } \\
\text { dose every } 3 \text { weeks }\end{array}$ & 425 & 2.8 & \multirow[t]{2}{*}{$\begin{array}{l}\text { HR: } \\
0.95\end{array}$} & 13.8 & \multirow[t]{2}{*}{$\begin{array}{l}\text { HR: } \\
0.73\end{array}$} & $55 \%$ & $14 \%$ & $15 \%$ & \multirow[t]{2}{*}{ [57] } \\
\hline & & $\begin{array}{c}\text { Docetaxel } 75 \mathrm{mg} / \mathrm{m}^{2} \text { every } 3 \\
\text { weeks }\end{array}$ & 425 & 4.0 & & 9.6 & & $41 \%$ & $13 \%$ & $43 \%$ & \\
\hline \multirow[t]{2}{*}{$\begin{array}{l}\text { JAVELIN } \\
\text { Lung } 200\end{array}$} & \multirow[t]{2}{*}{$\begin{array}{l}\text { Both with } \\
\text { PD-LI } \geq \text { I }\end{array}$} & $\begin{array}{c}\text { Avelumab } 10 \mathrm{mg} / \mathrm{kg} \text { every } 2 \\
\text { weeks }\end{array}$ & 264 & 2.8 & \multirow[t]{2}{*}{$\begin{array}{l}\text { HR: } \\
\text { I.16 }\end{array}$} & II.4 & \multirow[t]{2}{*}{$\begin{array}{l}\text { HR: } \\
0.90\end{array}$} & & $19 \%$ & $10 \%$ & \multirow[t]{2}{*}{ [59] } \\
\hline & & $\begin{array}{c}\text { Docetaxel } 75 \mathrm{mg} / \mathrm{m}^{2} \text { every } 3 \\
\text { weeks }\end{array}$ & 265 & 4.2 & & 10.3 & & & $12 \%$ & $49 \%$ & \\
\hline
\end{tabular}

Note: *The I-year progression-free survival was $19 \%$ for nivolumab and $8 \%$ for docetaxel.

Abbreviations: PD-LI, programmed cell death ligand-I; mPFS, median progression-free survival; mOS, median overall survival; OS, overall survival; ORR, overall response rate; TRAE, treatment-related adverse event. 
docetaxel (12.2 versus 9.4 months; HR: 0.73, $p=0.002$ ). Median PFS was 2.3 months for nivolumab compared to 4.2 months for docetaxel, with initial crossing of the curves; however, the 1-year PFS was $19 \%$ for nivolumab and $8 \%$ for docetaxel. This result was partly explained by the mechanism of action of ICIs, which have a later efficacy than cytotoxic drugs. Nivolumab was associated with longer OS and PFS, and higher ORR than docetaxel at the prespecified PD-L1 expression levels of $\geq 1 \%, \geq 5 \%$ and $\geq 10 \%$. However, in contrast to the results in squamous tumors, no difference in OS was observed between the two groups in patients with PD-L1-negative tumors. ${ }^{52}$ TRAEs of grade 3-4 were more frequently observed in the nivolumab group than in the docetaxel group in both studies.

From the 5-year pooled data of CheckMate 017 and CheckMate 057, 5-year OS rates were 13.4\% for nivolumab and $2.6 \%$ for docetaxel. In patients with an objective response to nivolumab, $32.2 \%$ continued to have a response at 5 years. The median duration of response was 19.9 months in patients treated with nivolumab compared with 5.6 months with docetaxel. ${ }^{53}$ These results demonstrate a long-term survival benefit with nivolumab compared to chemotherapy, with a significant five-fold increase in OS rate and no new safety signals.

Pembrolizumab also has a well-established efficacy in second-line treatment of advanced NSCLC. KEYNOTE 010 was an open-label, phase II-III trial, which randomized pretreated NSCLC patients 1:1:1 to receive pembrolizumab at two doses $(2 \mathrm{mg} / \mathrm{kg}$ and $10 \mathrm{mg} / \mathrm{kg}$ ) or docetaxel (Table 3). Patients with either squamous or non-squamous carcinomas could be enrolled in this trial, but were required to have a PD-L1 TPS $\geq 1 \%$. In this trial, median OS was 10.4 months with pembrolizumab at $2 \mathrm{mg} / \mathrm{kg}, 12.7$ months with pembrolizumab at $10 \mathrm{mg} / \mathrm{kg}$ and 8.5 months with chemotherapy. OS was significantly longer for pembrolizumab $2 \mathrm{mg} / \mathrm{kg}$ versus docetaxel (HR: 0.71, $p=0.0008$ ) and for pembrolizumab $10 \mathrm{mg} / \mathrm{kg}$ versus docetaxel (HR: $0.61, p<0.0001$ ). Patients with high PD-L1 expression showed greater benefit with pembrolizumab, ${ }^{54}$ highlighting the correlation with the effectiveness of the treatment that was FDA approved for patients with PD-L1 positive tumors.

In updated results at median follow-up of 42.6 months, pembrolizumab continued to be associated with improved OS over docetaxel (HR: 0.53 for PD-L1 $\geq 50 \%$; and HR: 0.69 for PD-L1 $\geq 1 \%) .{ }^{55}$ Median OS was 16.9 months versus 8.2 months in the PD-L1 $\geq 50 \%$ group and 11.8 versus 8.4 months in the PD-L1 $\geq 1 \%$ group. OS at 36 months was also higher in the pembrolizumab arm than in the docetaxel arm. Long-term outcomes were evaluated in patients receiving up to 35 cycles/2 years or second-course pembrolizumab at disease progression after 2 years. In the first group, patients showed durable responses, and OS rates at 12 and 24 months after completing 35 cycles were $98.7 \%$ and $86.3 \%$, respectively; median OS was not reached. Fourteen patients treated with second-course of pembrolizumab had significant disease control rate (78.6\%), with five patients (35.7\%) completing the 17 cycles of therapy. Overall, these data highlight the efficacy of 2 years of pembrolizumab and the activity of the drug as a rechallenge strategy. ${ }^{55}$

Atezolizumab was also approved as a single agent for second-line treatment. The randomized phase II POPLAR and phase III OAK trials of atezolizumab versus docetaxel in previously treated NSCLC reported improved efficacy in the atezolizumab $\operatorname{arm}^{56,57}$ (Table 3). Of note, these studies evaluated PD-L1 expression on tumor cells (TCs) or tumor-infiltrating immune cells (ICs).

In the OAK trial, primary endpoints were OS in the ITT population and PD-L1 expression populations (TC1/2/ 3 or IC1/2/3). Atezolizumab, administered at a flat dose of $1200 \mathrm{mg}$ every 3 weeks, met the co-primary endpoints and significantly improved OS versus docetaxel in both populations, regardless of histology, and showed a favorable safety profile. The outcomes were better in the PD-L1high subgroup of patients (TC3 or IC3) (median OS: 20.5 versus 8.9 months; HR: 0.41); nevertheless, patients in the PD-L1-low or undetectable subgroup also had improved survival with atezolizumab (median OS 12.6 versus 8.9 months, HR: 0.75). Median PFS and ORR were similar between the two treatment groups in the ITT population; however, a significantly longer DOR was observed with atezolizumab. Efficacy and safety outcomes from both trials at long-term follow-up demonstrated a consistent survival benefit of atezolizumab over docetaxel, regardless of PD-L1 expression, and despite the fact that most patients in the docetaxel arm received subsequent immunotherapy. In the POPLAR trial, median OS was 12.6 versus 9.7 months (HR: 0.76), and in the OAK trial 13.3 versus 9.8 months (HR: 0.78 ) with atezolizumab and docetaxel, respectively. The 4-year OS rates were also improved with pembrolizumab. No new toxicities with longer follow-up were reported. ${ }^{58}$

Another anti-PD-L1 agent, avelumab, was compared to docetaxel in the same setting in the randomized, openlabel, multicenter, phase III JAVELIN Lung 200 trial. 
The median OS was not significantly different between the two groups, even in the subgroup with positive tumor PDL1 expression (Table 3). In the discussion, the authors provided various possible explanations for these negative data, including that a high percentage of patients in the control arm received immunotherapy after docetaxel. ${ }^{59}$

Treatment with ICIs currently represents the best choice after first-line chemotherapy. No comparison trial between these drugs has been performed; however, a recent meta-analysis shows no significant differences in terms of OS among nivolumab, pembrolizumab and atezolizumab. $^{60,61}$

\section{Current and Future Biomarkers for Outcomes with ICls in NSCLC}

Treatment with immune ICIs currently represents the standard of care in several advanced tumor types. In clinical trials, as well as in clinical practice, the use of ICIs has been shown to confer significant and durable responses and to prolong survival outcomes compared to chemotherapy. ${ }^{62}$

However, objective responses to immunotherapeutic agents are not yet satisfactory and some patients develop rapid disease progression. Moreover, some patients experience severe adverse effects related to ICIs, suggesting that the risk/benefit ratio should be carefully considered. The identification of predictive biomarkers of response to ICIs remains a fundamental need to select patients who can derive clinical benefit and to avoid toxicities to those who do not benefit from these drugs.

PD-L1 expressed on tumor cells has, so far, been the only predictive biomarker validated in clinical practice for ICI therapy in NSCLC. Beyond PD-L1, an increasing number of novel predictive biomarkers has emerged, despite limitations of research deriving from paucity of tumor tissue from small biopsies in metastatic NSCLC. ${ }^{63}$ In this context, liquid biopsy has proven to be a viable alternative to tumor tissue for non-invasive evaluation of the tumor genomic profile. ${ }^{64}$ Among the biomarkers already identified, there are "tumor-related biomarkers" such as PD-L1 and TMB, "biomarkers related to the tumor microenvironment", such as tumor-infiltrating lymphocytes (TILs), and "host-derived biomarkers", including circulating immune cells, soluble markers and gut microbiome. $^{65}$

As previously commented, several studies in NSCLC in different treatment settings have demonstrated an increase in response rates and better survival outcomes with different monoclonal antibodies, anti-PD-1 and PDL1, in patients with higher PD-L1 expression on tumor cells or immune cells. Currently, four PD-L1 assays are FDA approved in lung cancer. However, many questions have been raised about the predictive value of PD$\mathrm{L} 1{ }^{55,66,67}$ as suggested by the fact that clinical benefit can also be seen in patients whose tumors do not express PD-L1. First, for each PD-1/PD-L1 blocking agent, different monoclonal antibodies and cut-off values in immunohistochemistry (IHC) assays have been developed to define PD-L1 positivity, thus probably explaining the discrepancies in results between studies. ${ }^{68}$ Another issue could be identified in differences in sample processing and preservation across different laboratories. In addition, a single tissue sample may not be representative of the whole tumor because NSCLC is characterized by a high intratumoral heterogeneity, and it has also been demonstrated that the expression of PD-L1 is dynamic and can change over the course of treatment. ${ }^{69}$

Intertumor heterogeneity of PD-L1 expression should also be considered. Low TPS concordance rates between primary tumors and paired metastatic lymph nodes have been demonstrated by assessing PD-L1 expression with

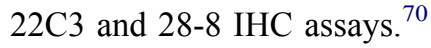

Another fundamental evaluation is that PD-L1 is an inducible biomarker and the predictive value may depend on the mechanism of its induction. ${ }^{71}$

Oncogenic alterations in lung tumors may cause an intrinsic elevation of PD-L1 expression, thus probably influencing the response to ICIs. ${ }^{72}$ Data on the efficacy of ICI plus chemotherapy combinations show that all patient populations benefit in terms of survival, regardless of PD-L1 expression or histological subtype. ${ }^{43,45,73}$ This suggests that the predictive value of PD-L1 expression may be lower than expected when using combinatorial strategies.

A study published in 2018, which conducted an analysis of a subgroup of KRAS-mutated lung adenocarcinomas that express co-mutations of STKL11 ( $L K B 1)$, showed that these alterations are the most prevalent genomic driver of primary resistance to PD-1/PD-L1 axis inhibitors. ${ }^{74}$ Additional activating gene mutations, including $B R A F$ and $A R I D I A$ mutations, may play an important role as predictors of response to immune checkpoint blockade therapy. Indeed, ARIDIA alterations assessed by next generation sequencing in different cancer types, including NSCLC, were associated with longer PFS 
after checkpoint blockade, regardless of microsatellite instability or TMB. ${ }^{63}$ Studies have shown that high baseline levels of the soluble form of PD-L1 (sPD-L1) in advanced NSCLC are significantly correlated with worse prognosis. ${ }^{75,76}$

The TMB, that is the total number of somatic mutations per coding area on the genome of tumor cells, has also been largely evaluated as a predictive biomarker. High TMB reflects a high number of neoantigens, conferring immunogenicity to the tumor, thereby influencing the response to cancer immunotherapy. It can be assessed by whole exome sequencing, whole genome sequencing and next generation sequencing using tumor tissue (tTMB) or blood (bTMB). Among the causes of increasing TMB, microsatellite instability (MSI) is included, generally related to mismatch repair deficiency (MMRD). Clinical trials demonstrated a high response rate and long-term benefit in patients who received ICI treatment, ${ }^{77,78}$ even though MSI is rarely found in NSCLC. ${ }^{79}$ The number of somatic mutations varies significantly between different cancer types and a significant correlation has been observed between the TMB and the ORR $(p<0.001)$ to anti-PD-1 or anti-PD-L1 monotherapy in patients with various tumors not selected for PD-L1 tumor expression. ${ }^{80}$

In NSCLC, a higher TMB was observed in smokingrelated tumors, which present more neoantigens on the surface of the cancer cells, thus causing increased immunogenicity and resulting in major sensitivity to treatment with immune checkpoint agents. ${ }^{81}$ Different studies have shown that patients with high TMB treated with ICIs benefit not only in the ORR, but also in PFS and OS. $^{41,82}$ A multimodal predictive model incorporating TMB by whole exome sequencing, activating mutations in receptor tyrosine kinase (RTK) mutations, smokingrelated mutational signature and human leukocyte antigen status, was correlated with the response to immune checkpoint blockade in an appealing study. ${ }^{63}$ The presence of RTK mutations (EGFR mutations) was a negative predictor of response, suggesting the importance of implementing comprehensive genomic analyses of NSCLC. Several studies have also tested the efficacy of various ICIs in different settings evaluating TMB status in blood samples with different cut-off levels of mut/Mb. ${ }^{83-85}$ Anyway, there are still unclear elements in considering TMB as a predictive biomarker, for example the cut-off of number of mutations to define high TMB status, variability in sample type and the lack of standardized platforms for its valuation.
New technologies in the field of radiomics suggest new options for the non-invasive evaluation of the tumor expression of PD-L1 and TMB, and studies are underway to validate the possible use of these methods both to evaluate the objective response and to predict clinical outcomes with ICIs in NSCLC patients. ${ }^{86,87}$

Other effective biomarkers could be identified in host immune system cells, both infiltrating the tumor and circulating. Tumor-infiltrating lymphocytes (TILs) are a constituent part of the tumor microenvironment, which constantly evolves during the tumor's natural history, and their functional orientation seems to depend on the microenvironment context. ${ }^{88}$ Preclinical and clinical studies have shown that levels of TILs significantly correlate with prognosis in NSCLC; in particular, high $\mathrm{CD} 8^{+} \mathrm{TIL}$ levels are correlated with prolonged survival. ${ }^{89}$ Furthermore, TILs were validated as a favourable prognostic marker for survival in resected NSCLC. ${ }^{90}$ It was also shown that the expression of PD-1 in TILs is significantly associated with the expression of its ligand, PD-L1, on tumor cells and tumor-infiltrating immune cells. ${ }^{91}$

Herbst et al observed that the association of PD-L1 expression by infiltrating immune cells with OR to atezolizumab was stronger than that with tumor PD-L1 expression. These results suggested that a pre-existing T-cell activity suppression could play a more critical role than induced-PD-L1 expression on tumor cells in mediating the response to this anti-PD-L1 monoclonal antibody. ${ }^{92}$ The possible predictive role during ICI treatment is also supported by the fact that several studies confirmed the role of $\mathrm{CD}^{+}$TILs as biomarkers of response to nivolumab in advanced NSCLC, demonstrating benefits in terms of RR and PFS. ${ }^{93,94}$ Among circulating immune cells, $\mathrm{CD}^{+}$ $\mathrm{T}$ lymphocytes have been investigated as biomarkers for efficacy in ICI treatment, with interesting results. In particular, the proliferation of circulating PD- $1^{+} \mathrm{CD} 8^{+} \mathrm{T}$ cells has been evaluated, demonstrating a better outcome in patients with NSCLC receiving PD-1-targeted therapies, with high levels of these after 1-4 weeks of treatment. ${ }^{95,96}$ Conversely, a high neutrophil to lymphocyte ratio (NLR) at baseline has demonstrated a negative predictive value of response to immunotherapy in several cancer types, including NSCLC. ${ }^{97}$ The gene expression signatures proved to be promising in the identification of immunogenic tumors, in particular those associated with the IFN- $\gamma$ gene signature. A clinical trial in patients with NSCLC treated with durvalumab demonstrated that patients with an IFN- $\gamma$-positive signature had higher ORR, and longer 
median PFS and OS compared with signature-low patients. The IFN- $\gamma$-positive mRNA signature may assist in identifying patients with improved outcomes with durvalumab, independent of PD-L1 expression. ${ }^{98}$ Positive results have also been observed in clinical trials with pembrolizumab ${ }^{99}$ and atezolizumab. ${ }^{47}$ Soluble systemic proteins were also evaluated as possible biomarkers, demonstrating promising results. In a meta-analysis evaluating NSCLC patients treated with ICIs, high levels of lactate dehydrogenase before treatment were significantly correlated with shorter PFS and OS. ${ }^{100}$

A retrospective study demonstrated that C-reactive protein over the upper limit of normal, in patients who were treated with anti-PD-1 agents, was a strong indicator for poor PFS and OS both in NSCLC and in the whole population. ${ }^{101}$ Low albumin level was also related to poor response to ICIs,${ }^{102}$ and an increase in TNF and IFN- $\gamma$ during ICI therapy resulted in better outcome. ${ }^{103}$ Other key genes involved in crucial pathways regulating immune response, including endocytosis, PD-L1 glycosylation, metabolic rewiring and the cGAS-STING pathway, can potentially correlate with response to ICIs (reviewed in ref. $^{63}$ ).

\section{Perspectives}

A number of novel immunotherapeutic approaches are being evaluated in NSCLC. Inhibitors of additional immune checkpoint molecules, such as lymphocyteactivation gene-3 (LAG-3) and T-cell immunoglobulin and mucin domain-3 (TIM-3), involved in T-cell suppression, are also being tested in clinical trials. Elevated LAG3 expression on $\mathrm{T}$ cells in baseline samples of NSCLC patients treated with PD-1 inhibitors was significantly associated with shorter PFS. ${ }^{104}$ The association of LAG3 and PD-1 inhibitors may be able to overcome resistance and enhance responses, as suggested by preliminary results of the CA224-020 clinical trial (NCT01968109) including melanoma patients who had progressed on prior anti-PD -1/PD-L1 therapy. In this study, LAG-3 expression on immune cells was predictive of clinical benefit from this combination. ${ }^{105}$ Phase II studies with the anti-LAG-3 inhibitor relatlimab, in association with nivolumab, are ongoing in early-stage and advanced NSCLC (NCT04205552, NCT02750514).

The use of modified T-cell therapy with chimeric antigen receptor (CAR)-T cells, already approved by the FDA for the treatment of hematological B-cell malignancies, has emerged as a promising strategy in solid tumors, including NSCLC. ${ }^{106,107}$ CAR-T cells are T cells genetically engineered to produce and express on their surface a CAR capable of recognizing and binding to specific antigens (such as CD19) on tumor cells. The targeted antigens exploited in NSCLC that are being tested in phase I and II clinical trials include EGFR, mesothelin, mucin 1, PD-L1, CD80/CD86 and inactive tyrosineprotein kinase transmembrane receptor (ROR1). ${ }^{107}$ However, treatment with CAR-T cells in solid tumors can have several limitations, including the heterogeneity of antigens expressed by tumor cells and the presence of an immunosuppressive tumor microenvironment that exhausts CAR-T cells. Intriguingly, the combination with ICIs can enhance the efficacy of CAR-T-cell therapy by modulating the immune inhibitory environment. ${ }^{108}$

Gene-edited T-cell therapy with clustered regularly interspaced short palindromic repeats (CRISPR)-Cas9 technology represents another appealing approach in lung cancer. Indeed, results from the first-in-human phase I clinical trial evaluating the role of CRISPR-Cas9 PD1-edited T cells in stage IIIB or IV, PD-L1-positive, heavily pretreated NSCLC patients demonstrated the safety and feasibility of this approach, thus paving the way for further investigation. ${ }^{109}$ However, there are several challenges that should be addressed before clinical implementation of this method. ${ }^{110}$

\section{Conclusions}

The results derived from a large number of studies on ICIs have significantly changed the therapeutic strategy for tumors in the past decade, and particularly for lung cancer, which has proven to be one of the best scenarios for application of this type of treatment, with significantly improved long-term survival outcomes. Immunotherapy has an established role in locally advanced and metastatic NSCLC and has also emerged as an effective strategy in patients with early-stage disease. In the neoadjuvant setting, different ICIs have been demonstrated to induce significant rates of tumor objective responses, including in N2 disease, and pathological responses that could predict better survival outcomes for these patients. However, results from ongoing phase III trials are awaited to define the optimal therapeutic approach for stage I-III NSCLC.

Despite the overall benefit in terms of efficacy and the safety profile of immunotherapy, limited responses are still observed, and a proportion of patients do not benefit from treatment and develop early disease progression. 
For this reason, great efforts have been made to further understand the mechanisms of immune evasion and identify predictive biomarkers that could be used, combined or individually, to select those patients most likely to respond to these agents and to better address the therapeutic choice. The use of biomarkers can result in improved clinical outcomes while potentially avoiding serious toxicities with these drugs. Neoadjuvant studies, which allow the response to treatment to be monitored not only with objective parameters but also through the characterization of tumor cells and the tumor microenvironment in surgical samples, are producing interesting results.

Better elucidation of the mechanisms of acquired resistance can potentially lead to biomarkers for treatment interventions. In this context, the use of liquid biopsy, in parallel with tumor tissue, could be useful to better track tumor genomic evolution over ICI therapy and monitor the emergence of resistance. A number of combinatorial treatment strategies, developed to improve single-agent efficacy and potentially delay or overcome resistance, have entered clinical practice, and these include the association of different classes of ICIs or of ICIs and chemotherapy. However, beyond the efficacy results, the toxicity of these combinations needs to be carefully assessed.

Novel immunotherapeutic approaches are emerging, with the potential to enhance the efficacy of ICIs and further improve patients' clinical outcomes.

\section{Disclosure}

The authors report no conflicts of interest in this work.

\section{References}

1. Sung H, Ferlay J, Siegel RL, et al. Global cancer statistics 2020: GLOBOCAN estimates of incidence and mortality worldwide for 36 cancers in 185 countries. CA Cancer J Clin. 2021;71(3):209-249. doi:10.3322/caac. 21660

2. Hanna NH, Robinson AG, Temin S, et al. Therapy for stage IV non-small-cell lung cancer with driver alterations: ASCO and $\mathrm{OH}$ (CCO) joint guideline update. J Clin Oncol. 2021;39(9):1040-1091. doi:10.1200/JCO.20.03570

3. Wei SC, Levine JH, Cogdill AP, et al. Distinct cellular mechanisms underlie anti-CTLA-4 and anti-PD-1 checkpoint blockade. Cell. 2017;170(6):1120-1133.e17. doi:10.1016/j.cell.2017.07.024

4. Huang Z, Su W, Lu T, et al. First-line immune-checkpoint inhibitors in non-small cell lung cancer: current landscape and future progress. Front Pharmacol. 2020;11:578091. doi:10.3389/fphar.2020.578091

5. Sha D, Jin Z, Budczies J, Kluck K, Stenzinger A, Sinicrope FA. Tumor mutational burden as a predictive biomarker in solid tumors. Cancer Discov. 2020;10(12):1808-1825. doi:10.1158/2159-8290.CD-20-0522

6. Fiala O, Šorejs O, Pešek M, Fínek J. Imunoterapie v léčbě karcinomu plic [Immunotherapy in the treatment of lung cancer]. Klin Onkol. 2017;30(Supplementum3):22-31.
7. Galon J, Angell HK, Bedognetti D, et al. The continuum of cancer immunosurveillance: prognostic, predictive, and mechanistic signatures. Immunity. 2013;39(1):11-26. doi:10.1016/j. immuni.2013.07.008

8. Palucka K, Banchereau J. Cancer immunotherapy via dendritic cells. Nat Rev Cancer. 2012;12(4):265-277. doi:10.1038/nrc3258

9. Pardoll DM. The blockade of immune checkpoints in cancer immunotherapy. Nat Rev Cancer. 2012;12(4):252-264. doi:10.1038/nrc3239

10. Sznol M, Chen L. Antagonist antibodies to PD-1 and B7-H1 (PD-L1) in the treatment of advanced human cancer. Clin Cancer Res. 2013;19(5):1021-1034. doi:10.1158/1078-0432. CCR-12-2063

11. Kim JM, Chen DS. Immune escape to PD-L1/PD-1 blockade: seven steps to success (or failure). Ann Oncol. 2016;27 (8):1492-1504. doi:10.1093/annonc/mdw217

12. Ackermann CJ, Reck M, Paz-Ares L, et al. First-line immune checkpoint blockade for advanced non-small-cell lung cancer: travelling at the speed of light. Lung Cancer. 2019;134:245-253. doi:10.1016/j.lungcan.2019.06.007

13. Parsa AT, Waldron JS, Panner A, et al. Loss of tumor suppressor PTEN function increases B7-H1 expression and immunoresistance in glioma. Nat Med. 2007;13(1):84-88. doi:10.1038/nm1517

14. Marzec M, Zhang Q, Goradia A, et al. Oncogenic kinase NPM/ ALK induces through STAT3 expression of immunosuppressive protein CD274 (PD-L1, B7-H1). Proc Natl Acad Sci U S A. 2008;105(52):20852-20857. doi:10.1073/pnas.0810958105

15. Atefi M, Avramis E, Lassen A, et al. Effects of MAPK and PI3K pathways on PD-L1 expression in melanoma. Clin Cancer Res. 2014;20(13):3446-3457. doi:10.1158/1078-0432.CCR-13-2797

16. Akbay EA, Koyama S, Carretero J, et al. Activation of the PD-1 pathway contributes to immune escape in EGFR-driven lung tumors. Cancer Discov. 2013;3(12):1355-1363. doi:10.1158/ 2159-8290.CD-13-0310

17. Wu Z, Man S, Sun R, et al. Recent advances and challenges of immune checkpoint inhibitors in immunotherapy of non-small cell lung cancer. Int Immunopharmacol. 2020;85:106613. doi:10.1016/j.intimp.2020.106613

18. Lawrence MS, Stojanov P, Polak P, et al. Mutational heterogeneity in cancer and the search for new cancer-associated genes. Nature. 2013;499(7457):214-218. doi:10.1038/nature12213

19. Topalian SL, Hodi FS, Brahmer JR, et al. Safety, activity, and immune correlates of anti-PD-1 antibody in cancer. $N$ Engl $J$ Med. 2012;366(26):2443-2454.

20. Brahmer JR, Tykodi SS, Chow LQ, et al. Safety and activity of anti-PD-L1 antibody in patients with advanced cancer. $N$ Engl J Med. 2012;366(26):2455-2465. doi:10.1056/NEJMoa1200694

21. Uramoto H, Tanaka F. Recurrence after surgery in patients with NSCLC. Transl Lung Cancer Res. 2014;3,4:242-249.

22. Lim E, Harris G, Patel A, Adachi I, Edmonds L, Song F. Preoperative versus postoperative chemotherapy in patients with resectable non-small cell lung cancer: systematic review and indirect comparison meta-analysis of randomized trials. $J \quad$ Thorac Oncol. 2009;4(11):1380-1388. doi:10.1097/ JTO.0b013e3181b9ecca

23. Pignon JP, Tribodet H, Scagliotti GV, et al. Lung adjuvant cisplatin evaluation: pooled analysis by LACE Collaborative Group. $J \quad$ Clin Oncol. 2008;26(21):3552-3559. doi:10.1200/ JCO.2007.13.9030

24. Forde PM, Chaft JE, Smith KN, et al. Neoadjuvant PD-1 blockade in resectable lung cancer [published correction appears in N Engl J Med. 2018 Nov 29;379(22):2185]. N Engl J Med. 2018;378(21):1976-1986. doi:10.1056/NEJMoa1716078

25. Gao S, Li N, Gao S, et al. Neoadjuvant PD-1 inhibitor (Sintilimab) in NSCLC. J Thorac Oncol. 2020;15(5):816-826. doi:10.1016/j.jtho.2020.01.017 
26. Cascone T, William WN Jr, Weissferdt A, et al. Neoadjuvant nivolumab or nivolumab plus ipilimumab in operable non-small cell lung cancer: the phase 2 randomized NEOSTAR trial. Nat Med. 2021;27(3):504-514. doi:10.1038/s41591-020-01224-2

27. Kwiatkowski DJ, Rusch VW, Chaft JE, et al. Neoadjuvant atezolizumab in resectable non-small cell lung cancer (NSCLC): interim analysis and biomarker data from a multicenter study (LCMC3). J Clin Oncol. 2019;37(suppl 15):8503. doi:10.1200/ JCO.2019.37.15_suppl.8503

28. Lee JM. Surgical and clinical outcomes with neoadjuvant atezolizumab in resectable stage IB-IIIB NSCLC: LCMC3 trial primary analysis. Presented at: 2020 World Conference on Lung Cancer Singapore; January 28-31; Virtual. Abstract 3195.

29. Shu CA, Gainor JF, Awad MM, et al. Neoadjuvant atezolizumab and chemotherapy in patients with resectable non-small-cell lung cancer: an open-label, multicentre, single-arm, phase 2 trial. Lancet Oncol. 2020;21(6):786-795. doi:10.1016/S1470-2045(20) 30140-6

30. Provencio M, Nadal E, Insa A, et al. Neoadjuvant chemotherapy and nivolumab in resectable non-small-cell lung cancer (NADIM): an open-label, multicentre, single-arm, phase 2 trial. Lancet Oncol. 2020;21(11):1413-1422. doi:10.1016/S14702045(20)30453-8

31. Antonia SJ, Villegas A, Daniel D, et al. Durvalumab after chemoradiotherapy in stage III non-small-cell lung cancer. $N$ Engl J Med. 2017;377(20):1919-1929. doi:10.1056/NEJMoa1709937

32. Antonia SJ, Villegas A, Daniel D, et al. Overall survival with durvalumab after chemoradiotherapy in stage III NSCLC. $N$ Engl $J$ Med. 2018;379(24):2342-2350. doi:10.1056/NEJMoa1809697

33. Deng L, Liang H, Burnette B, et al. Irradiation and anti-PDL1 treatment synergistically promote antitumor immunity in mice. J Clin Invest. 2014;124(2):687-695. doi:10.1172/JCI67313

34. Reck M, Rodríguez-Abreu D, Robinson AG, et al. Pembrolizumab versus chemotherapy for PD-L1-positive non-small-cell lung cancer. $N$ Engl J Med. 2016;375 (19):1823-1833. doi:10.1056/NEJMoa1606774

35. Reck M, Rodríguez-Abreu D, Robinson AG, et al. Five-year outcomes with pembrolizumab versus chemotherapy for metastatic non-small-cell lung cancer with PD-L1 tumor proportion score $\geq 50$. J Clin Oncol. 2021:JCO2100174. doi:10.1200/ JCO.21.00174

36. Carbone DP, Reck M, Paz-Ares L, et al. First-line nivolumab in stage IV or recurrent non-small-cell lung cancer. $N$ Engl J Med. 2017;376(25):2415-2426.). doi:10.1056/NEJMoa1613493

37. Herbst RS, Giaccone G, de Marinis F, et al. Atezolizumab for first-line treatment of PD-L1-selected patients with NSCLC. $N$ Engl J Med. 2020;383(14):1328-1339. doi:10.1056/ NEJMoa1917346

38. Verschraegen CF, Jerusalem G, McClay EF, et al. Efficacy and safety of first-line avelumab in patients with advanced non-small cell lung cancer: results from a phase Ib cohort of the JAVELIN Solid Tumor Study. J Immunother Cancer. 2020;8(2):e001064. doi:10.1136/jitc-2020-001064

39. Hellmann MD, Rizvi NA, Goldman JW, et al. Nivolumab plus ipilimumab as first-line treatment for advanced non-small-cell lung cancer (CheckMate 012): results of an open-label, Phase 1, Multicohort Study. Lancet Oncol. 2017;18(1):31-41. doi:10.1016/ S1470-2045(16)30624-6

40. Ready N, Hellmann MD, Awad MM, et al. First-line nivolumab plus ipilimumab in advanced non-small-cell lung cancer (CheckMate 568): outcomes by programmed death ligand 1 and tumor mutational burden as biomarkers. J Clin Oncol. 2019;37 (12):992-1000. doi:10.1200/JCO.18.01042

41. Hellmann MD, Paz-Ares L, Bernabe Caro R, et al. Nivolumab plus ipilimumab in advanced non-small-cell lung cancer. $N$ Engl J Med. 2019;381(21):2020-2031. doi:10.1056/NEJMoa1910231
42. Rizvi NA, Cho BC, Reinmuth N, et al. Durvalumab with or without tremelimumab vs standard chemotherapy in first-line treatment of metastatic non-small cell lung cancer: the MYSTIC phase 3 randomized clinical trial. JAMA Oncol. 2020;6 (5):661-674. doi:10.1001/jamaoncol.2020.0237

43. Gandhi L, Rodríguez-Abreu D, Gadgeel S, et al. Pembrolizumab plus chemotherapy in metastatic non-small-cell lung cancer. $N$ Engl J Med. 2018;378(22):2078-2092. doi:10.1056/ NEJMoa1801005

44. Gadgeel S, Rodríguez-Abreu D, Speranza G, et al. Updated analysis from KEYNOTE-189: pembrolizumab or placebo plus pemetrexed and platinum for previously untreated metastatic nonsquamous non-small-cell lung cancer. J Clin Oncol. 2020;38 (14):1505-1517. doi:10.1200/JCO.19.03136

45. Paz-Ares L, Luft A, Vicente D, et al. Pembrolizumab plus chemotherapy for squamous non-small-cell lung cancer. $N$ Engl J Med. 2018;379(21):2040-2051. doi:10.1056/NEJMoa1810865

46. Paz-Ares L, Vicente D, Tafreshi A, et al. A randomized, placebo-controlled trial of pembrolizumab plus chemotherapy in patients with metastatic squamous NSCLC: protocol-specified final analysis of KEYNOTE-407. J Thorac Oncol. 2020;15 (10):1657-1669. doi:10.1016/j.jtho.2020.06.015

47. Socinski MA, Jotte RM, Cappuzzo F, et al. Atezolizumab for first-line treatment of metastatic nonsquamous NSCLC. $N$ Engl J Med. 2018;378(24):2288-2301. doi:10.1056/NEJMoa1716948

48. Paz-Ares L, Ciuleanu TE, Cobo M, et al. First-line nivolumab plus ipilimumab combined with two cycles of chemotherapy in patients with non-small-cell lung cancer (CheckMate 9LA): an international, randomised, open-label, phase 3 trial [published correction appears in Lancet Oncol. 2021 Mar;22(3):e92]. Lancet Oncol. 2021;22(2):198-211.

49. Johnston RJ, Comps-Agrar L, Hackney J, et al. The immunoreceptor TIGIT regulates antitumor and antiviral CD8(+) T cell effector function. Cancer Cell. 2014;26(6):923-937. doi:10.1016/ j.ccell.2014.10.018

50. Rodriguez-Abreu D, Johnson ML, Hussein MA, et al. Primary analysis of a randomized, double-blind, phase II study of the anti-TIGIT antibody tiragolumab (tira) plus atezolizumab (atezo) versus placebo plus atezo as first-line (1L) treatment in patients with PD-L1-selected NSCLC (CITYSCAPE). J Clin Oncol. 2020;38(suppl 15):9503. doi:10.1200/JCO.2020.38.15_su ppl.9503

51. Brahmer J, Reckamp KL, Baas P, et al. Nivolumab versus docetaxel in advanced squamous-cell non-small-cell lung cancer. $N$ Engl J Med. 2015;373(2):123-135. doi:10.1038/nrc3245

52. Borghaei H, Paz-Ares L, Horn L, et al. Nivolumab versus docetaxel in advanced nonsquamous non-small-cell lung cancer. $N$ Engl J Med. 2015;373(17):1627-1639. doi:10.1056/ NEJMoa1507643

53. Borghaei H, Gettinger S, Vokes EE, et al. Five-year outcomes from the randomized, phase III trials checkmate 017 and 057: nivolumab versus docetaxel in previously treated non-small-cell lung cancer [published correction appears in J Clin Oncol. 2021 Apr 1;39(10):1190]. J Clin Oncol. 2021;39(7):723-733. doi:10.1200/JCO.20.01605

54. Herbst RS, Baas P, Kim DW, et al. Pembrolizumab versus docetaxel for previously treated, PD-L1- positive, advanced nonsmall-cell lung cancer (KEYNOTE-010): a randomised controlled trial. Lancet. 2016;387(10027):1540-1550. doi:10.1016/S01406736(15)01281-7

55. Herbst RS, Garon EB, Kim DW, et al. Long-term outcomes and retreatment among patients with previously treated, programmed death-ligand 1-positive, advanced non-small-cell lung cancer in the KEYNOTE-010 Study. J Clin Oncol. 2020;38 (14):1580-1590. doi:10.1200/JCO.19.02446 
56. Fehrenbacher L, Spira A, Ballinger M, et al. Atezolizumab versus docetaxel for patients with previously treated non-small-cell lung cancer (POPLAR): a multicentre, open-label, phase 2 randomised controlled trial. Lancet. 2016;387(10030):1837-1846. doi:10.1016/S0140-6736(16)00587-0

57. Rittmeyer A, Barlesi F, Waterkamp D, et al. Atezolizumab versus docetaxel in patients with previously treated non-small-cell lung cancer (OAK): a phase 3, open-label, multicentre randomised controlled trial [published correction appears in Lancet. 2017 Apr 8;389(10077):e5]. Lancet. 2017;389(10066):255-265. doi:10.1016/S0140-6736(16)32517-X

58. Mazieres J, Rittmeyer A, Gadgeel S, et al. Atezolizumab versus docetaxel in pretreated patients with NSCLC: final results from the randomized phase 2 POPLAR and phase 3 OAK clinical trials. $J$ Thorac Oncol. 2021;16(1):140-150. doi:10.1016/j. jtho.2020.09.022

59. Barlesi F, Vansteenkiste J, Spigel D, et al. Avelumab versus docetaxel in patients with platinum-treated advanced non-smallcell lung cancer (JAVELIN Lung 200): an open-label, randomised, phase 3 study [published correction appears in Lancet Oncol. 2018 Nov;19(11):e581]. Lancet Oncol. 2018;19 (11):1468-1479. doi:10.1016/S1470-2045(18)30673-9

60. Armoiry X, Tsertsvadze A, Connock M, et al. Comparative efficacy and safety of licensed treatments for previously treated nonsmall cell lung cancer: a systematic review and network metaanalysis. PLoS One. 2018;13(7):e0199575. doi:10.1371/journal. pone. 0199575

61. Tan PS, Aguiar P Jr, Haaland B, Lopes G. Comparative effectiveness of immune-checkpoint inhibitors for previously treated advanced non-small cell lung cancer-a systematic review and network meta-analysis of 3024 participants. Lung Cancer. 2018;115:84-88. doi:10.1016/j.lungcan.2017.11.017

62. Santarpia M, Giovannetti E, Rolfo C, et al. Recent developments in the use of immunotherapy in non-small cell lung cancer. Expert Rev Respir Med. 2016;10(7):781-798. doi:10.1080/17476348.20 16.1182866

63. Santarpia M, Aguilar A, Chaib I, et al. Non-small-cell lung cancer signaling pathways, metabolism, and PD-1/PD-L1 antibodies. Cancers (Basel). 2020;12(6):1475.). doi:10.3390/cancers120 61475

64. Friedlaender A, Nouspikel T, Christinat Y, et al. Tissue-plasma tmb comparison and plasma TMB monitoring in patients with metastatic non-small cell lung cancer receiving immune checkpoint inhibitors. Front Oncol. 2020;10:142. doi:10.3389/ fonc. 2020.00142

65. Duchemann B, Remon J, Naigeon M, et al. Current and future biomarkers for outcomes with immunotherapy in non-small cell lung cancer. Transl Lung Cancer Res. 2020;10(6):2937.

66. Brahmer J, Horn L, Hossein B, et al. Long-term survival outcomes with nivolumab (NIVO) in pts with previously treated advanced non-small cell lung cancer (NSCLC): impact of early disease control and response. J Thorac Oncol. 2019;14(11): S1152-3. doi:10.1016/j.jtho.2019.09.089

67. Aguilar EJ, Ricciuti B, Gainor JF, et al. Outcomes to first-line pembrolizumab in patients with non-small-cell lung cancer and very high PD-L1 expression. Ann Oncol. 2019;30 (10):1653-1659. doi:10.1093/annonc/mdz288

68. Hirsch FR, McElhinny A, Stanforth D, et al. PDL1 immunohistochemistry assays for lung cancer: results from phase 1 of the blueprint PD-L1 IHC assay comparison project. J Thorac Oncol. 2017;12(2):208-222. doi:10.1016/j.jtho.2016.11.2228

69. McLaughlin J, Han G, Schalper KA, et al. Quantitative assessment of the heterogeneity of PD-L1 expression in non-small-cell lung cancer. JAMA Oncol. 2016;2(1):46-54. doi:10.1001/ jamaoncol.2015.3638
70. Saito $\mathrm{Y}$, Horiuchi S, Morooka H, et al. Inter-tumor heterogeneity of PD-L1 expression in non-small cell lung cancer. $J$ Thorac Dis. 2019;11(12):4982-4991. doi:10.21037/jtd.2019.12.24

71. Dong Z-Y, Wu S-P, Liao R-Q, et al. Potential biomarker for checkpoint blockade immunotherapy and treatment strategy. Tumour Biol. 2016;16(37):4251-4261. doi:10.1007/s13277-0164812-9

72. Mazieres J, Drilon A, Lusque A, et al. Immune checkpoint inhibitors for patients with advanced lung cancer and oncogenic driver alterations: results from the IMMUNOTARGET registry. Ann Oncol. 2019;30(8):1321-1328. doi:10.1093/annonc/mdz167

73. Gadgeel SM, Garassino MC, Esteban E, et al. KEYNOTE-189: updated OS and progression after the next line of therapy (PFS2) with pembrolizumab (pembro) plus chemo with pemetrexed and platinum vs placebo plus chemo for metastatic nonsquamous NSCLC. J Clin Oncol. 2019;37(15_suppl):9013. doi:10.1200/ JCO.2019.37.15_suppl.9013

74. Skoulidis F, Goldberg ME, Greenawalt DM, et al. STK11/LKB1 mutations and PD-1 inhibitor resistance in KRAS-mutant lung adenocarcinoma. Cancer Discov. 2018;8(7):822-835. doi:10.1158/2159-8290.CD-18-0099

75. Zhang J, Gao J, Li Y, et al. Circulating PD- L1 in NSCLC patients and the correlation between the level of PD-L1 expression and the clinical characteristics. Thorac Cancer. 2015;6(4):534-538. doi:10.1111/1759-7714.12247

76. Okuma Y, Hosomi Y, Nakahara Y, et al. High plasma levels of soluble programmed cell death ligand 1 are prognostic for reduced survival in advanced lung cancer. Lung Cancer. 2017;104:1-6. doi:10.1016/j.lungcan.2016.11.023

77. Le DT, Durham JN, Smith KN, et al. Mismatch repair deficiency predicts response of solid tumors to PD-1 blockade. Science. 2017;357(6349):409-413. doi:10.1126/science.aan6733

78. Petrelli F, Ghidini M, Ghidini A, Tomasello G. Outcomes following immune checkpoint inhibitor treatment of patients with microsatellite instability-high cancers: a systematic review and meta-analysis. JAMA Oncol. 2020;6(7):1068-1071. doi:10.1001/ jamaoncol.2020.1046

79. Warth A, Körner S, Penzel R, et al. Microsatellite instability in pulmonary adenocarcinomas: a Comprehensive Study of 480 cases. Virchows Arch. 2016;468(3):313-319. doi:10.1007/ s00428-015-1892-7

80. Yarchoan M, Hopkins A, Jaffee EM. Tumor mutational burden and response rate to PD-1 inhibition. $N$ Engl J Med. 2017;377 (25):2500-2501. doi:10.1056/NEJMc1713444

81. Rizvi NA, Hellmann MD, Snyder A, et al. Cancer immunology. Mutational landscape determines sensitivity to PD-1 blockade in non-small cell lung cancer. Science. 2015;348(6230):124-128.

82. Goodman AM, Sokol ES, Frampton GM, et al. Microsatellitestable tumors with high mutational burden benefit from immunotherapy. Cancer Immunol Res. 2019;7(10):1570-1573. doi:10.1158/2326-6066.CIR-19-0149

83. Gandara DR, Paul SM, Kowanetz M, et al. Blood-based tumor mutational burden as a predictor of clinical benefit in non-smallcell lung cancer patients treated with atezolizumab. Nat Med. 2018;24(9):1441-1448. doi:10.1038/s41591-018-0134-3

84. Rizvi NA, Chul Cho B, Reinmuth N, et al. Durvalumab with or without tremelimumab vs platinum-based chemotherapy as first-line treatment for metastatic non-small cell lung cancer: MYSTIC. Ann Oncol. 2018;29:mdy511.005-mdy511.005. doi:10.1093/annonc/mdy511.005

85. Peters $\mathrm{S}$, Cho BC, Reinmuth N, et al. Tumor mutational burden (TMB) as a biomarker of survival in metastatic non-small cell lung cancer (mNSCLC): blood and tissue TMB analysis from MYSTIC, a Phase III Study of first-line durvalumab \pm tremelimumab vs chemotherapy. Cancer Res. 2019;79:CT074. 
86. Tian $\mathrm{P}, \mathrm{He} \mathrm{B}, \mathrm{Mu} \mathrm{W}$, et al. Assessing PD-L1 expression in non-small cell lung cancer and predicting responses to immune checkpoint inhibitors using deep learning on computed tomography images. Theranostics. 2021;11(5):2098-2107. doi:10.7150/ thno. 48027

87. He B, Dong D, She Y, et al. Predicting response to immunotherapy in advanced non-small-cell lung cancer using tumor mutational burden radiomic biomarker. J Immunother Cancer. 2020;8 (2):e000550. doi:10.1136/jitc-2020-000550

88. Fridman WH, Pagès F, Sautès-Fridman C, Galon J. The immune contexture in human tumours: impact on clinical outcome. Nat Rev Cancer. 2012;12:298-306.

89. Zeng DQ, Yu YF, Ou QY, et al. Prognostic and predictive value of tumor-infiltrating lymphocytes for clinical therapeutic research in patients with non-small cell lung cancer. Oncotarget. 2016;7 (12):13765-13781. doi:10.18632/oncotarget.7282

90. Brambilla E, Le Teuff G, Marguet S, et al. Prognostic effect of tumor lymphocytic infiltration in resectable non-small-cell lung cancer. J Clin Oncol. 2016;34(11):1223-1230. doi:10.1200/ JCO.2015.63.0970

91. Santarpia M, Karachaliou N. Tumor immune microenvironment characterization and response to anti-PD-1 therapy. Cancer Biol Med. 2015;12(2):74-78.

92. Herbst RS, Soria J-C, Kowanetz M, et al. Predictive correlates of response to the anti-PD-L1 antibody MPDL3280A in cancer patients. Nature. 2014;515(7528):563-567. doi:10.1038/ nature 14011

93. Sahba S, Niemeijer A-L, De Langen J, et al. Association of tumor and stroma PD-1, PD-L1, CD3, CD4 and CD8 expression with response to nivolumab treatment in NSCLC patients. Ann Oncol. 2017;28:107P. doi:10.1093/annonc/mdx363.023

94. Gataa I, Mezquita L, Auclin E, et al. Pathological evaluation of tumor infiltrating lymphocytes and the benefit of nivolumab in advanced non-small cell lung cancer (NSCLC). Ann Oncol. 2017;28:112P. doi:10.1093/annonc/mdx363.028

95. Kim $\mathrm{KH}, \mathrm{Cho} \mathrm{J}, \mathrm{Ku} \mathrm{BM}$, et al. The first-week proliferative response of peripheral blood $\mathrm{PD}-1+\mathrm{CD} 8+\mathrm{T}$ cells predicts the response to anti-pd-1 therapy in solid tumors. Clin Cancer Res. 2019;25(7):2144-2154. doi:10.1158/1078-0432.CCR-18-1449

96. Kamphorst AO, Pillai RN, Yang S, et al. Proliferation of PD-1+ CD8 T cells in peripheral blood after PD-1- targeted therapy in lung cancer patients. Proc Natl Acad Sci. 2017;114 (19):4993-4998. doi:10.1073/pnas.1705327114

97. Diem S, Schmid S, Krapf M, et al. Neutrophil-to-Lymphocyte ratio (NLR) and platelet-to-lymphocyte ratio (PLR) as prognostic markers in patients with non-small cell lung cancer (NSCLC) treated with nivolumab. Lung Cancer. 2017;111:176-181. doi:10.1016/j.lungcan.2017.07.024
98. Higgs BW, Morehouse CA, Streicher K, et al. Interferon gamma messenger RNA signature in tumor biopsies predicts outcomes in patients with non-small cell lung carcinoma or urothelial cancer treated with durvalumab. Clin Cancer Res. 2018;24 (16):3857-3866. doi:10.1158/1078-0432.CCR-17-3451

99. Ayers M, Lunceford J, Nebozhyn M, et al. IFN- $\gamma$-related mRNA profile predicts clinical response to PD-1 blockade. J Clin Invest. 2017;127(8):2930-2940.

100. Zhang Z, Li Y, Yan X, et al. Pretreatment lactate dehydrogenase may predict outcome of advanced non small-cell lung cancer patients treated with immune checkpoint inhibitors: a meta-analysis. Cancer Med. 2019;8(4):1467-1473. doi:10.1002/ cam4.2024

101. Iivanainen S, Ahvonen J, Knuuttila A, et al. Elevated CRP levels indicate poor progression-free and overall survival on cancer patients treated with PD-1 inhibitors. ESMO Open. 2019;4(4): e000531. doi:10.1136/esmoopen-2019-000531

102. Shoji F, Takeoka H, Kozuma Y, et al. Pretreatment prognostic nutritional index as a novel biomarker in non-small cell lung cancer patients treated with immune checkpoint inhibitors. Lung Cancer. 2019;136:45-51. doi:10.1016/j.lungcan.2019.08.006

103. Costantini A, Julie C, Dumenil C, et al. Predictive role of plasmatic biomarkers in advanced non-small cell lung cancer treated by nivolumab. Oncoimmunology. 2018;7:e1452581. doi:10.1080/ 2162402X.2018.1452581

104. Ortiz A, Gui J, Zahedi F, et al. An interferon-driven oxysterol-based defense against tumor-derived extracellular vesicles. Cancer Cell. 2019;35(1):33-45.e36. doi:10.1016/j.ccell.2018.12.001

105. Larsen TV, Hussmann D, Nielsen AL. PD-L1 and PD - L2 expression correlated genes in non-small-cell lung cancer. Cancer Commun. 2019;39(1):30. doi:10.1186/s40880-019-0376-6

106. Titov A, Valiullina A, Zmievskaya E, et al. Advancing CAR T-cell therapy for solid tumors: lessons learned from lymphoma treatment. Cancers (Basel). 2020;12(1):125. doi:10.3390/cancers 12010125

107. Qu J, Mei Q, Chen L, Zhou J. Chimeric antigen receptor (CAR)-T-cell therapy in non-small-cell lung cancer (NSCLC): current status and future perspectives. Cancer Immunol Immunother. 2021;70(3):619-631. doi:10.1007/s00262-020-02735-0

108. Grosser R, Cherkassky L, Chintala N, Adusumilli PS. Combination immunotherapy with CAR $\mathrm{T}$ cells and checkpoint blockade for the treatment of solid tumors. Cancer Cell. 2019;36 (5):471-482. doi:10.1016/j.ccell.2019.09.006

109. Lu Y, Xue J, Deng $\mathrm{T}$, et al. Safety and feasibility of CRISPR-edited $\mathrm{T}$ cells in patients with refractory non-small-cell lung cancer. Nat Med. 2020;26(5):732-740. doi:10.1038/s41591020-0840-5

110. Asmamaw M, Zawdie B. Mechanism and applications of CRISPR/Cas-9-mediated genome editing. Biologics. 2021;15:353-361.

\section{Publish your work in this journal}

Biologics: Targets and Therapy is an international, peer-reviewed journal focusing on the patho-physiological rationale for and clinical application of Biologic agents in the management of autoimmune diseases, cancers or other pathologies where a molecular target can be identified. This journal is indexed on PubMed Central, CAS, EMBase,
Scopus and the Elsevier Bibliographic databases. The manuscript management system is completely online and includes a very quick and fair peer-review system, which is all easy to use. Visit http://www.dovepress.com/testimonials.php to read real quotes from published authors. 